\title{
Papal visits and abortions: evidence from Italy
}

\section{Egidio Farina $^{1}$ (D) . Vikram Pathania ${ }^{2}$}

Received: 5 September 2018 / Accepted: 31 October 2019 /Published online: 31 December 2019

(C) The Author(s) 2019

\begin{abstract}
We investigate the impact of papal visits to Italian provinces on abortions from 1979 to 2012. Using administrative data, we find a 10-20\% decrease in the number of abortions that commences in the 3rd month and persists until the 14th month after the visits. However, we find no significant change in the number of live births. A decline in unintended pregnancies best explains our results. Papal visits generate intense local media coverage, and likely make salient the Catholic Church's stance against abortions. We show that papal visits lead to increased church attendance, and that the decline in abortions is greater when the Pope mentions abortion in his speeches.
\end{abstract}

Keywords Abortion · Religion · Pope $\cdot$ Culture $\cdot$ Fertility

JEL Classification D91 $\cdot \mathrm{J} 13 \cdot \mathrm{Z} 12$

\section{Introduction}

Through history, religion has shaped societies and has been, and in many cases continues to be, a key factor in how people make major life choices. The economics of religion is a young but fast-growing field of research that employs economic theory and econometric techniques to better understand the interaction between religion and society (Iannaccone 1998; McCleary and Barro 2006; Iyer 2016). In this paper, we investigate the link between religion and abortions. Each day, approximately 153,000 pregnancies are terminated around the world (Sedgh et al. 2016). While access to abortion

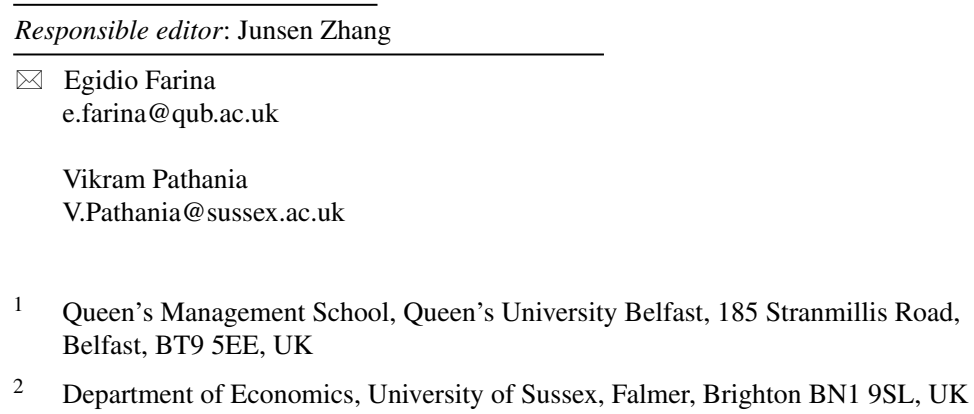


has become more widely available in an increasing number of countries, abortion remains a controversial procedure. In many countries, women who abort face religious sanctions, legal restrictions and hostile social norms (Norris et al. 2011). The decision to undergo an abortion is often associated with considerable stress and anxiety. For example, Coleman et al. (2009) show that women who abort are at a higher risk of a variety of mental health problems, including anxiety, mood and substance abuse disorders, when compared with women without a history of abortion.

We measure the causal impact of papal visits to Italian provinces between 1979 and 2012 on the number of abortions. Our choice to focus on Italy is motivated by three factors. First, Italy is predominantly Catholic and the Pope is the emblem of Catholic doctrine. Second, due to the geographical proximity of the Vatican, Italy is the country with the highest number of papal visits, viz. 129 in our sample period, increasing the statistical power of our research design. Finally, since 1979, the Italian National Institute of Statistics has collected information on all abortions in Italy with a high detail of geographical identification, allowing us to construct a monthly panel of abortion counts at the provincial level.

We employ an event study methodology to measure the impact of a papal visit to an Italian province. Our main result is a large and statistically significant drop in the number of abortions starting from the 3rd month after a papal visit and persisting until about the 14th month. Specifically, we measure a decline in monthly abortion counts that ranges from about 10 to $20 \%$. Ceteris paribus, a decline in abortions should be accompanied by a subsequent spike in live births. However, we fail to detect a significant increase in births after the papal visit. This is surprising for at least two reasons. First, as we detail later, a back of the envelope calculation predicts that, if there is no change in the number of pregnancies, live births should increase by about $3.7 \% 6$ to 7 months after the decline in abortions. Our null result on the number of births is rather precise; the upper bound of the $95 \%$ confidence interval is about $1.2 \%$. Second, independently of the effect on abortions, papal visits would be expected to boost fertility in the short run through an increase in desired fertility or reduced contraceptive usage. Indeed, Bassi and Rasul (2017) document a spike in births in Brazil 9 months after the papal visit in 1992.

Why would papal visits lead to a drop in abortions? Catholic Church doctrine strongly condemns deliberate termination of pregnancy. According to the Donum Vitae:

"Human life is sacred because from its beginning it involves the creative action of God and it remains for ever in a special relationship with the Creator, who is its sole end. God alone is the Lord of life from its beginning until its end: no one can under any circumstance claim for himself the right directly to destroy an innocent human being" (Ratzinger 1987).

Papal visits can heighten the stigma attached to abortion, leading to both direct and indirect effects on the number of abortions. By direct effect, we mean a reduced probability of abortion, conditional on becoming unintentionally pregnant. This can be mediated through a drop in the demand for and in the supply of abortions. Women may be more reluctant to abort. Alternatively, stigma could drive women to opt for "back-street" abortions to keep the procedure secret, which would cause 
under-reporting. Abortion providers may also become more reluctant to do the procedure unless medically necessary. In contrast, the indirect effect is a reduction in the number of abortions due to a decrease in the number of unintended pregnancies if women choose more abstinence or use more contraception. ${ }^{1}$

The intuition of the indirect effect is readily confirmed in a simple model of contraceptive usage that builds on Levine (2004). In this model, women are forward looking and fully informed of their personal costs of abortion vs. birth in the case of an unintended pregnancy. They choose an optimal level of contraception, which can include abstinence. Papal visits increase the perceived cost of abortion. The model predicts that women respond by increasing contraceptive usage, thereby reducing the number of unintended pregnancies, which in turn reduces the number of abortions.

For two main reasons, we argue that it is the indirect effect rather than the direct effects that drive our results. First, the direct effects should show up as a decline in abortions that is contemporaneous with the papal visit. There is no such contemporaneous drop. In contrast, if there is a decline in unintended pregnancies that begins with a papal visit, it would manifest itself with a decrease in abortions 2-3 months after the papal visit since pregnancies are typically detected 6-8 weeks after conception. ${ }^{2}$ Second, as noted already, we find no significant increase in births after the papal visit. If there are fewer abortions, births must mechanically increase unless the number of pregnancies is also falling. ${ }^{3}$

The proximate causes of a fall in unintended pregnancies could be increased abstinence, or alternatively, increased usage of contraceptives during intercourse. Since the Catholic Church frowns upon sexual relations unless in the context of procreation, that could also directly increase abstinence. Women may also opt for more use of contraceptives, although that can pose a dilemma since the Catholic Church has traditionally opposed contraception. It is conceivable that some women decide that contraception is the "lesser of two evils".

We furnish supporting evidence that papal visits make the Catholic doctrine highly salient and increase the perceived cost of abortion. While one might think that Italians are "accustomed" to the papal presence, as he lives in Rome and often visits Italian provinces, we document that papal visits within Italy dominate local media coverage and generate considerable excitement among the local clergy and the population alike. Furthermore, the impact on abortions appears to be larger when the Pope refers to abortion in his speeches and when he engages more intensively with the public. We also find that the visits result in higher religiosity in the local population as proxied by church attendance.

This paper contributes to a number of different literatures. First, we shed additional light on the determinants of abortion. The economic literature on abortions can be

\footnotetext{
${ }^{1}$ Henceforth, when we mention women, we imply women or couples as the relevant decisions on engaging in sexual intercourse, using contraception, or deciding to abort are likely to involve not just the woman but also her partner.

${ }^{2}$ The vast majority of voluntary terminations of pregnancy occur in the second or third month.

${ }^{3}$ A significant fraction of unintended pregnancies lead to live births. Singh et al. (2010) estimate that in 2008 in Southern Europe, 39\% of all pregnancies were unintended. Of these, just over $40 \%$ were aborted. About $48 \%$ were carried to term and resulted in live births. The remaining ended as miscarriages.
} 
traced back to seminal work by Becker (1991) and Rosenzweig and Schultz (1983). They model children as an investment producing benefits over time. Contraception and abortion are seen as methods for achieving the number of children desired by the household. Several studies have explored how the demand for abortion responds to changes in public policies. Blank et al. (1996) and Levine et al. (1996) show that the enactment of restrictions on Medicaid funding is correlated with a decline in abortion rates in the USA. Joyce and Kaestner (1996) show that parental involvement laws have no impact on the probability of abortion for minors in the USA, with the only exception of South Carolina, where a negative and statistically significant effect is found for 16-year-old non-Blacks. Levine (2003) finds that parental involvement laws reduce abortion rates for younger teens, but not for older teens or adult women. Abramowitz (2018) finds that the provision of the Affordable Care Act for young adults, a health insurance reform enacted in the USA in 2010, causes a decrease in the probability of childbirth and in the abortion rate. A new stream of research has started to investigate the causal effects of "supply-side" policies that target abortion facilities Joyce (2011). Grossman et al. (2017) find that, among Texas counties with no abortion provider in 2014, larger increases in the distance to the nearest provider between 2012 and 2014 are associated with larger decreases in abortions. Lindo et al. (2017) find a large and non-linear reduction in abortion rates in response to increased distance to clinics from abortion clinic closures in Texas; they also find a substantial negative effect from increased congestion at the surviving clinics.

Second, we add to the strand of literature in the economics of religion that aims to pin down the causal effects of religion on important socio-economic outcomes. For example, a number of recent papers have exploited the exogenous timing of Ramadan-induced fasting to study effects on educational, health and labour market outcomes (Almond and Mazumder 2011; Oosterbeek and van der Klaauw 2013; Majid 2015). Clingingsmith et al. (2009) exploit the lottery-based allocation of Hajj visas in Pakistan to identify the impact of Hajj on religiosity and social attitudes. In an experimental study, Benjamin et al. (2016) randomly prime subjects to make their religious identity salient and find that this causes subjects to identify more closely with their religion, and in turn affects their economic choices. Our paper is closely related to a recent paper by Bassi and Rasul (2017) on the effect of the 1991 papal visit on fertility-related beliefs and behaviour in Brazil. The authors report a significant increase in the hazard rate for births 9 months post-visit. We complement Bassi and Rasul (2017) using administrative records to study the impact of papal visits on abortion and to a lesser extent births. To the best of our knowledge, no study before has sought to measure the effect of heightened religious sentiment on the number of abortions or used administrative data to precisely estimate the effect of the papal visits on the number of births.

Finally and more broadly, the paper contributes to a growing literature focused on the impact of role models on behaviour. Beaman et al. (2009) and Beaman et al. (2012) show that exposure to a female politician reduces gender stereotypes and influences adolescent girls' career aspirations and educational attainment. DellaVigna (2010) uses an event study methodology to explore how Obama's election affects racial discrimination against Blacks and economic outcomes for Blacks by changing perceptions of Blacks. Bertrand and Schoar (2003) analyse how individual managers 
affect corporate behaviour and performance. Jones and Olken (2005) investigate the impact of national leaders on economic growth. Stroebel and van Benthem (2012) use the appointment of local bishops in Kenya to study the impact of church authorities' teaching on sexual behaviour.

The paper is organised as follows. We present the institutional setting in Section 2. In Section 3, we describe the data on abortion and the papal visits. Next in Section 4, we sketch a simple model of contraceptive usage, and spell out the predictions for the number of unintended pregnancies, abortions and live births in response to a change in the perceived cost of abortion. Regression results for the number of abortions and live births are presented in Section 5. In Section 6, we investigate plausible mechanisms that could be driving the results. In particular, we show that papal visits within Italy generate widespread coverage in local media, there appears to be an increase in religiosity as measured by church attendance, and the measured decline in abortion is greater during visits where the Pope mentions abortion. We discuss and interpret our findings in Section 7. We also show that the timing of papal visits is not driven by short-run pre-existing province-level trends, bolstering the case for a causal interpretation of our results. Finally, we conclude in Section 8.

\section{Institutional setting}

Historically, the Catholic Church has exerted a strong influence on the Italian culture. For example, the current Italian education system requires the teaching of the Catholic religion in all schools below the university level due to the Lateran Treaties, an agreement between the Italian Kingdom and the Holy See signed by Mussolini during the fascist regime. Since the institutional referendum in 1946, in which the Italian population voted to abolish the monarchy, the Vatican tried to actively influence the political course of the republic. For example, in 1948, the Church supported the Christian Democratic party against the Communist Party presenting the election as a conflict between good and evil.

In 1974, the Italian Bishop Conference strongly supported the initiative in favour of the promotion of the referendum repealing the law on divorce passed in $1970 .{ }^{4}$ Similarly, after an abortion bill became law in 1978, the Pope and the Italian Bishops' Conference promoted the attempt to restrict abortion in the referendum proposed by the right-to-life movement in 1981.

Vezzoni and Biolcati-Rinaldi (2015) have documented a declining trend in religiosity in Italy since the late 1960s until 2010, in spite of a period of stability in the 1980s and 1990s. Nonetheless, Italy today remains a predominantly Catholic country; Catholics comprised $71 \%$ of the population in 2016 (Eurispes 2016).

According to the Catholic doctrine, family represents the original cell of social life, where individuals learn moral values from childhood. The creation of the nuclear family cannot prescind from marriage, seen as a covenant linking a man and a woman

\footnotetext{
${ }^{4}$ See for instance (Wertman 1982) who reports that the Italian Bishops' Conference issued a document arguing that opting for divorce would be an act of disobedience for Catholics.
} 
for the rest of their lives. Sexuality is only admitted within the wedlock, and if aimed at fulfilling the twofold obligation of the "good of the spouses" and the transmission of life. ${ }^{5}$ In the light of this perception adopted by the Church, divorces, the recourse to sterilisation, and the use of contraceptives and abortion are viewed as "a sign of the refusal that man gives to the love of God" (John Paul II 1981). Even with the decline in religiosity, Catholic doctrine still shapes popular opinion on abortion. In a survey from year 2016, 83.2\% of the people interviewed report to be in favour of the abortion in case of danger for the mother while only the $18.6 \%$ of people think abortion is acceptable if a woman does not want to have children (Eurispes 2016).

Voluntary pregnancy termination in Italy became legal in May 1978, with the approval of the Law 194/78 by the Italian Parliament. Abortions are performed freeof-charge in public hospitals or for a fee in private facilities authorised by the regional health authorities. Women at least 18 years old can request a termination of pregnancy during the first 90 days for health, economic or social reasons. For women below 18 , permission must be sought from their legal guardian or, in the event of refusal, a judge may intervene with an injunction, within 5 days of the request if there are sufficient legal reasons. Abortions are also allowed in the second and third trimesters of the pregnancy if the life of the woman would be at risk if the pregnancy is carried to term or the foetus presents genetic malformations which would expose the mother to a risk of serious psychological or physical consequences.

After a woman obtains the medical authorisation, a period of 7 days has to occur before the date of the abortion operation, unless an immediate intervention is required due to the presence of risks for the woman's health conditions. The abortion operation is generally performed 8 to 30 days after a woman obtains the medical authorisation. During the Question Time on 19 April 2017, the Minister of Health Beatrice Lorenzin claimed that $65.3 \%$ of voluntary pregnancy terminations are performed within 14 days from medical authorisation (Ministry of Health 2017).

Figure 1 compares the trend in the abortion rate, defined as the number of abortions per 1000 women aged 15-44, in Italy and the USA. While the rate in Italy is lower, it trends similarly except for a surge after legalisation in 1978.

\section{Data and descriptive statistics}

From 1979 to 2012, John Paul II and Benedict XVI made 129 official visits to 85 provinces within Italy. ${ }^{6}$ We generate an event binary indicator mapping each town visited by the Pope in a given quarter of year to the corresponding province. ${ }^{7}$ Due to

\footnotetext{
${ }^{5}$ See, for example, the Catechism of the Catholic Church (n.d.) at the following link: http://www.vatican. va/archive/ccc_css/archive/catechism/p3s2c2a6.htm.

${ }^{6}$ Since the change in the number of provinces over time could influence our results, as a robustness test we have analysed the impact of the papal visits on abortions, excluding the new provinces and the preexisting ones affected by the creation of the new administrative bodies. The outcome, available upon request, confirms the main results presented in Section 5.

${ }^{7}$ Italian provinces are administrative units between a municipality and a region, corresponding to NUTS3 regions according to the European Union classification. Several municipalities form a province while several provinces form a region (Valle d'Aosta is the sole exception, since the provincial functions are
} 


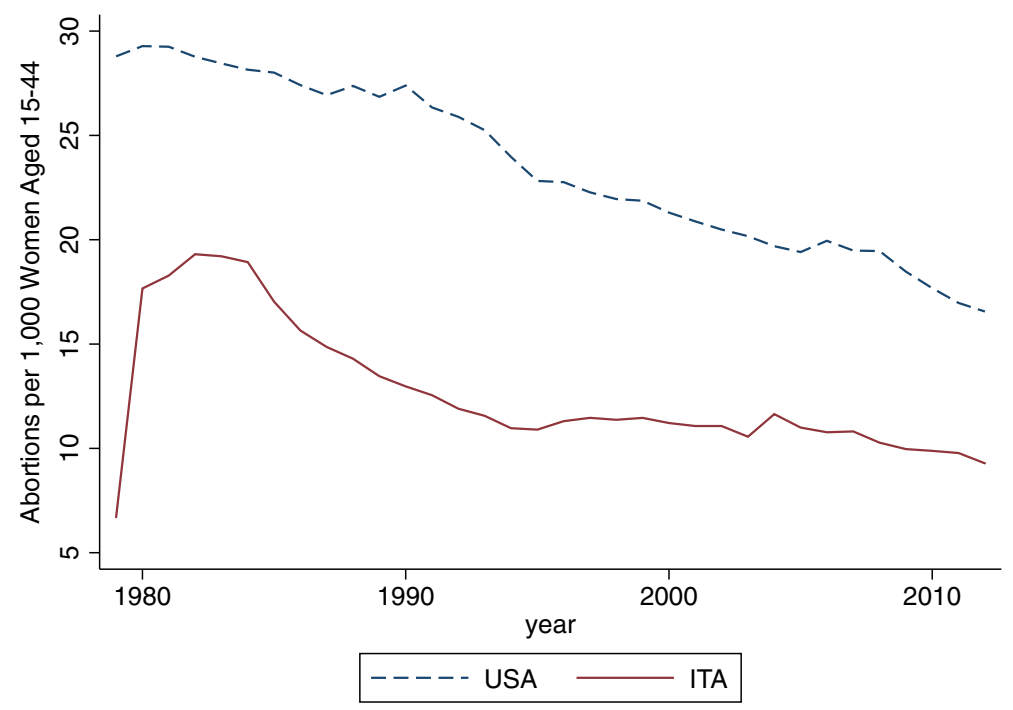

Fig. 1 Yearly abortion rate in Italy and the USA. The data on Italy are provided by ISTAT. The data for the USA are provided by the Johnston's archive (http://www.johnstonsarchive.net/policy/abortion/index.html)

the presence of multiple destinations within the same visit, we identify 173 episodes (called Pope Events hereafter) in which the Italian provinces were visited by the Pope in a given quarter of year.

The duration of the papal visits can vary from a single to multiple days. While there is no one standardised program across visits, they do share some common features. For example, after the Pope is welcomed by the delegates of the political institutions and the dioceses hosting the event, the Pope typically holds an open mass in public. The religious ceremony is generally followed by meetings with specific subgroups of the local population, such as the local youth, or by visits to hospitals and penitentiaries. Unlike the international visits, which hold an in-flight questionand-answer session with the press onboard the plane, in general the Pope does not address the local media directly, even though journalists are allowed to cover papal activities during the visit.

Summary statistics on the events are reported in Table 1; on average, the Pope visited just over 5 provinces in a year. The last two columns in Table 1 offer a comparison between John Paul II's papacy (column 2) and Benedict XVI's one (column 3 ). It is worth noting that the number of provinces visited per year by Pope John Paul II is on average higher than Benedict XVI's visits, reflecting John Paul's proverbial

exercised by the region). Provinces fulfil three main functions, i.e. local planning and zoning, provision of local police and fire services and, finally, transportation regulation such as car registration or maintenance of local roads. In 2012, there were 110 provinces, even though the number has been steadily growing in recent years. 
Table 1 Papal visits

\begin{tabular}{|c|c|c|c|}
\hline & (1) & (2) & (3) \\
\hline & All Visits & John Paul II & Benedict XVI \\
\hline & 1979-2012 & 1979-2004 & 2005-2012 \\
\hline No. of papal visits & 129 & 100 & 29 \\
\hline No. of pope events & 173 & 141 & 32 \\
\hline No. of provinces visited & 85 & 82 & 26 \\
\hline Pope events/year & 5.08 & 5.42 & 4 \\
\hline No. of provinces & 110 & 103 & 110 \\
\hline
\end{tabular}

Authors' calculations

higher propensity to travel; he was also known as the Globetrotter Pope or Voyager Pope (Danesi n.d.). The distribution of events across provinces over the study period is shown in Fig. 2.

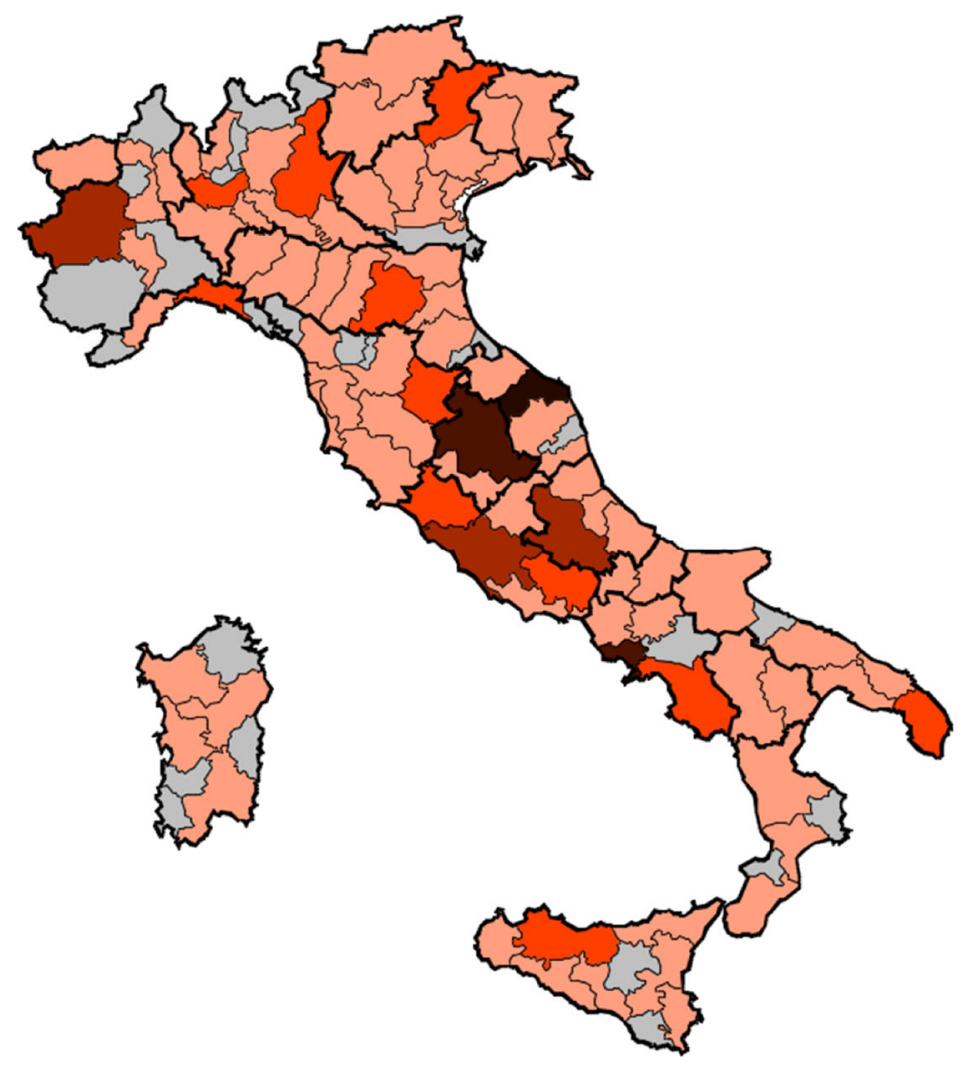

Papal visits

0

Visits $\leq 2$

Visits $\leq 4$

Visits $\leq 6$

Visits $\leq 8$

Visits $\leq 10$

Fig. 2 Papal visits to the Italian provinces 
Following the legalisation of abortion in Italy, the data on induced abortions performed in public and private clinics certified and authorised by the Italian regions are provided since 1979 by the Italian National Institute of Statistics together with the Italian regions and the Ministry of Health. The survey requires the doctor performing the termination of pregnancy to collect important information on the socio-economic status of the woman such as date and place of birth, place of residence, marital status, educational level and work status. Information on the operation are also provided, such as date of pregnancy interruption, province of the operation, length of stay in hospital and presence of complications.

The micro-data on abortions and on live births are securely maintained on the servers of the Italian National Institute of Statistics. For reasons of confidentiality, researchers are not permitted to copy and move the data elsewhere. All analysis must be conducted on-site with prior approval. All analytical results such as notes, tables, and figures are subject to stringent scrutiny before approval for release.

In Table 2, we present summary statistics on abortions stratified by age, the education level and marital status of women. Unsurprisingly, the abortion ratio, conventionally defined as $a / b$ where $a$ and $b$ are the counts of voluntary abortions and

Table 2 Abortions by women's demographics

(1)

Abortions

Panel A - Age category

Not reported

Age $\leq 19$

$20 \leq$ Age $\leq 24$

$25 \leq$ Age $\leq 29$

$30 \leq$ Age $\leq 34$

$35 \leq$ Age $\leq 39$

Age $\geq 40$

Panel B - Education Lv.

Not reported

Elementary school

Lower secondary school

Upper secondary school

Higher education

Panel C - Marital status

Unmarried

Married

N
$2,125,774$

120.53

$\begin{array}{ll}12,100 & 10.71 \\ 460,932 & 99.02 \\ 993,223 & 32.72 \\ 1,128,878 & 20.52 \\ 1,121,674 & 21.39 \\ 926,822 & 34.96 \\ 490,988 & 82.37\end{array}$

280,175

$1,345,696$

$2,172,676$

$1,188,268$

147,802

3, 008,843

19.18

$5,134,617$

9.02

2.72

29.16
(2)

Abortion ratio (\%)

Column 1 reports the number of abortions from 1979 to 2012 for each subcategory. Column 2 displays the abortion ratio defined as abortions / births 
live births, respectively, is the highest for teenagers (99.02\%) and unmarried women $(120 \%)$. Presumably, there is a large overlap between the two groups. The abortion ratio is also high for women aged 40 years or more, presumably on medical grounds since pregnancies tend to be riskier for older women. While the abortion ratio is much higher for unmarried women, married women account for the majority (about $59 \%$ ) of abortions. Also, women who have completed lower secondary school education, corresponding to 8 years of education including elementary school, account for almost $43 \%$ of all abortions. The abortion ratio cannot be calculated by educational attainment since this information is not available for mothers due to changes in data collection on births starting from 1999.

In Fig. 3, we present the number of yearly abortions for the period 1979-2012 at the national level. The strong increase in the early 1980s in response to the legalisation of abortion has been followed by a steady decrease over time. In Fig. 4, we plot the trend in annual number of live births for the same period. The plot documents the well-known decline in Italian fertility through the 1980s and 1990s. The sharp dip in 1997-1998 is an artefact of under-reporting of births. A new law in 1997 aimed at administrative simplification dramatically changed the data collection process, allowing parents to declare live births not only at the registers of the municipality where the birth event took place but also at the registers of the municipality where parents normally resided. The immediate application of this law, in the middle of 1997, caused a period of strong uncertainty which resulted in the under-reporting of live births for the years 1997-1998. We exclude those two years when we analyse the impact of papal visits on live births.

Comparing Figs. 3 and 4 provides an indication of the level and trend in the abortion ratio-it declines from over 35\% in the early 1980s to about $20 \%$ by 2012.

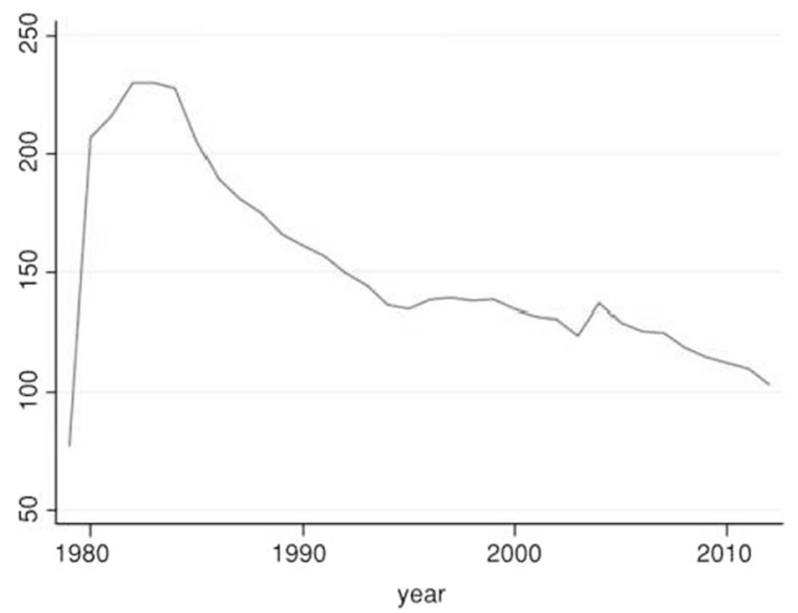

Fig. 3 Annual abortions in Italy (in thousands). The data on the annual number of abortions are provided by ISTAT 


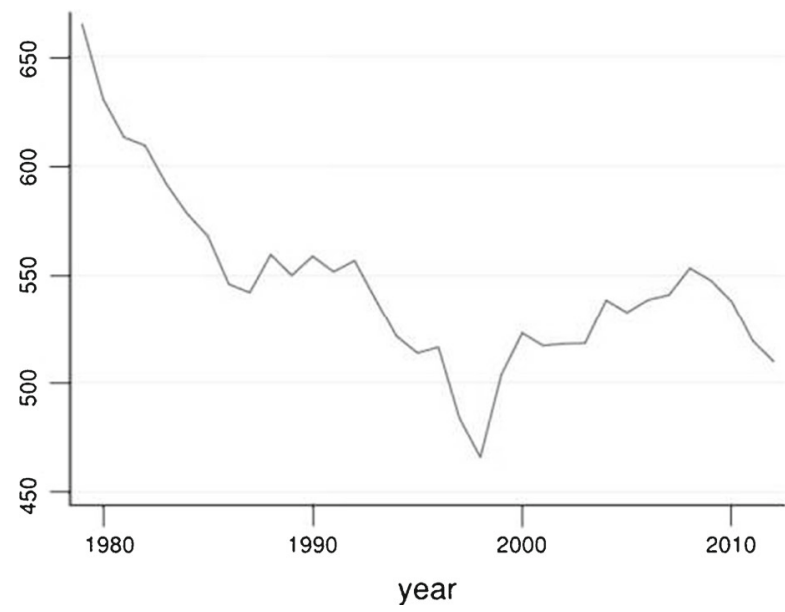

Fig. 4 Annual births in Italy (in thousands). The data on the annual number of births are provided by ISTAT

In order to study the impact of the visits of the Pope to the Italian provinces, we aggregate the number of abortions and births at the province-month (or provincequarter) level. Summary statistics of those counts are reported in Table 3.

Table 3 Abortions and births

Province-month

Province-quarter

Panel A

No. of abortions

127.25

381.75

(187.25)

N

40,470

Panel B

No. of births

459.30

$1,364.81$

(570.38)

$(1,684.02)$

N

37,998

12,666

The reported statistics are the mean and standard deviation (in parentheses) of the number of abortions (Panel A) or births (Panel B) at the province-month (column 1) or province-quarter (column 2) level for the years 1979 to 2012. The data for births exclude the years 1997 and 1998 since there was underreporting in those years due to the application of a new law on administrative simplification on birth registration which caused a period of uncertainty 


\section{Theoretical framework}

Papal visits plausibly make salient and heighten the stigma attached to abortion. This can affect the number of abortions through direct and indirect effects. The direct effect is the reduced probability of a woman getting an abortion, conditional on finding herself with an unintended pregnancy. This effect can work through reduced demand and/or supply. On the demand side, women may be less willing to abort. Alternatively (or additionally) there may be a constriction in supply, i.e. an increased reluctance of abortion providers to do the procedure. The direct effect predicts that abortions would start decreasing contemporaneously with the visit, and the number of live births would increase starting 6 to 7 months after the visit. ${ }^{8}$

The indirect effect is a behavioural change that reduces the probability of an unintended pregnancy. Specifically, women may choose to increase the use of contraceptives (possibly including more abstinence) to guard against unintended pregnancies, so that they do not have to face the dilemma of abortion. ${ }^{9}$

Most pregnancies are detected 6 to 8 weeks after conception, and it presumably takes another 2-3 weeks to decide and schedule an abortion. Therefore, a decline in unintended pregnancies that starts contemporaneously with the papal visit would show up as a decline in abortions about 2-3 months later. It is not immediately obvious whether the indirect effect causes births to increase or decrease. On one hand, fewer unintended pregnancies should reduce the number of births, given a fixed fraction of such pregnancies being aborted. On the other hand, births could increase if unintended pregnancies are aborted at a lower rate.

To formalise our intuition about the indirect effect, we build on the discussion in Levine (2004) to develop a simple model of contraception. Women who are not planning to have a baby choose $c$, a measure of contraceptive intensity, i.e. the level of precaution exercised to prevent conception. Note that increased abstinence is also a form of contraception. This is costly; let $f(c)$ be the cost of contraceptive intensity with $f^{\prime}>0$.

Contraception is not completely effective; let $p(c)$ be the probability that the woman conceives as a function of $c$. Obviously, $p^{\prime}<0$.

If the woman conceives, she has to decide whether to abort or have the baby. Each woman is denoted by a type $\{a, b\}$ where $a$ and $b$ are the woman-specific costs of aborting and having a baby, respectively. We assume perfect foresight, i.e. each woman correctly perceives these costs before she pick $c$. Then, if the woman conceives, she aborts if $a<b$, else she decides to have the baby.

A woman picks $c$ to minimise $f(c)+p(c) \min \{a, b\}$.

\footnotetext{
${ }^{8} \mathrm{~A}$ woman who is 2 months pregnant at the time of the visit, and decides against abortion because of the visit, will give birth 7 months after the visit.

${ }^{9}$ Abortions are most likely to occur in the case of unintended pregnancies. They could also occur in planned pregnancies on medical grounds or if the woman or couple changes its mind. However, most abortions are related to unintended pregnancies. For instance, Finer and Henshaw (2006) indicate that less than 5\% of abortions in the USA were were intended pregnancies at the time of conception. Likewise, Schünmann and Glasier (2006) find that $92 \%$ of women undergoing an abortion operation in Scotland did not plan their pregnancy.
} 
We analyse the impact of an increase in the perceived cost of abortion $a_{1}>a$ for three relevant types of women.

\section{Type I (never-aborters): $b<a$}

Such women will pick $c$ to minimise $f(c)+p(c) b \Longrightarrow f^{\prime}\left(c^{*}\right)=-p^{\prime}\left(c^{*}\right) b$. If the woman conceives, she will opt to give birth. Importantly, if there is an increase in the cost of abortion, this will not affect $c^{*}$. For such women, there is no effect on either the number of abortions ( 0 before and after) or the number of births.

\section{Type II (always-aborters): $a<a_{1}<b$}

Before the change in cost of abortion, such women pick $c$ to minimise $f(c)+$ $p(c) a \Longrightarrow f^{\prime}\left(c^{*}\right)=-p^{\prime}\left(c^{*}\right) a$. If the woman conceives, she will abort. In this case, an increase in the cost of abortion will affect $c^{*}$, although it will not change the decision to abort if contraception fails.

The implicit function theorem yields the direction of change in $c^{*}$ :

$$
\begin{aligned}
f^{\prime}(c) & =-p^{\prime}(c) a \\
f^{\prime \prime}(c) \frac{\partial c}{\partial a} & =-p^{\prime}(c)-p^{\prime \prime}(c) a \frac{\partial c}{\partial a} \\
\frac{\partial c}{\partial a} & =\frac{-p^{\prime}(c)}{f^{\prime \prime}(c)+p^{\prime \prime}(c) a}
\end{aligned}
$$

The numerator is positive. The denominator is also positive as it is the secondorder condition for an interior solution to the minimisation problem. Thus, $c^{*}$ increases and $p$ decreases. ${ }^{10}$

This reduces number of unintended pregnancies and the number of abortions. There is no effect on the number of births which stay 0 before and after.

Type III (switchers): $a<b<a_{1}$

Such women will switch from aborting to having a baby when the cost of abortion rises. However, the optimal $c$ will also change. Since the cost of pregnancy has increased, the argument presented in case II holds in this case as well, and $c^{*}$ increases and thus $p$ decreases. The number of unintended pregnancies will fall. But these pregnancies will no longer be aborted. Therefore, there will be an unambiguous decrease in the number of abortions and an increase in the number of births.

\footnotetext{
${ }^{10}$ We can also show that $c^{*}$ is weakly increasing in the cost of abortion $a$ under weaker conditions (Topkis 1978). Define the woman's objective function: $F(c, a)=f(c)+p(c) \min \{a, b\}$. We need to show that for any $c_{1}>c$ and any $a_{1}>a$ that:

$$
\begin{aligned}
F\left(c_{1}, a_{1}\right)-F\left(c, a_{1}\right) & \leq F\left(c_{1}, a\right)-F(c, a) \\
\Longrightarrow\left[p\left(c_{1}\right)-p(c)\right] \min \left\{a_{1}, b\right\} & \leq\left[p\left(c_{1}\right)-p(c)\right] \min \{a, b\} .
\end{aligned}
$$

Since $p\left(c_{1}\right) \leq p(c)$ and $\min ($.$) is an increasing function, the above is always true. Notice we made no$ assumptions about $f$. However, unless one assumes that $f$ and $p$ are strictly convex, the argmin (set of optimal $c$ ) need not be unique. In that case, the above condition guarantees that the argmin correspondence increases in $a$ with respect to the "strong set order". Intuitively, if $a_{1}>a$, then the lower (upper) bound of $\operatorname{argmin}$ at $a_{1}$ is higher that the lower (upper) bound of argmin at $a$ (the interval shifts to the right).
} 
Table 4 summarises the predicted impact of an increase in the cost of abortion on contraceptive usage, and the number of unintended pregnancies, abortions and births. Using available data, we can test the predictions of the model for the number of abortions and births. The model's predictions in the aggregate data depend upon the distribution of types in the population. We do not directly observe the types. But we know that in the absence of papal visits, a non-trivial fraction of unintended pregnancies are aborted, i.e. $a<b$ which implies that together, always-aborters and switchers make up a non-trivial fraction of women. This simple model predicts that an exogenous increase in the perceived cost of abortion reduces the number of abortions, through increased contraception that decreases the number of unintended pregnancies. Table 4 also suggests that whether we observe an increase in the number of births depends on the proportion of switchers.

The assumption of perfect foresight is not critical for the prediction of a decline in abortions. It is plausible that some women form naive priors about the costs of abortion and birth, and update only when they get pregnant. The perceived costs determine a woman's choice of contraceptive usage; the updated costs post-pregnancy do not factor in that decision. As long as the perceived $a_{1}>a$, the model predicts a decline in abortions.

\section{Regression results}

\subsection{Abortions}

To study the impact of the papal visits to the Italian provinces on the number of abortions, we estimate the following specification:

$\ln \left(n_{p, q}\right)=\alpha+\beta_{j}^{\text {pre }} \sum_{j=-1}^{j=-2} \operatorname{pre}_{j}+\beta_{k}^{\text {post }} \sum_{k=0}^{k=5} \operatorname{post}_{k}+\theta_{p}+\theta_{y}+\sum_{l=1}^{l=4} \lambda_{l}+\gamma_{p} \times t+\delta_{p} \times t^{2}+u_{p, q}$

where $n_{p, q}$ represents the number of abortions in province $p$ in the quarter of year $q$; pre $_{j}$ are placebo dummy variables capturing any impact of the papal visits on abortions in the two quarters prior to the visit; post $_{k}$ are post-event dummies enveloping the Pope Event ( post $_{0}=1$ ) up to the fifth quarter after the papal visits in a given province. $\theta_{p}$ and $\theta_{y}$ represent province and year fixed effects; $\lambda_{l}$ are calendar quarter

Table 4 Impact of an increase in the cost of abortion

\begin{tabular}{lllll}
\hline Case & $\Delta$ contraception & $\Delta$ (pregnancies) & $\Delta$ (abortions) & $\Delta$ (births) \\
\hline I: $b<a$ & 0 & 0 & 0 & 0 \\
II $a<a_{1}<b$ & + & - & - & 0 \\
III $a<b<a_{1}$ & + & - & - & + \\
\hline
\end{tabular}

$a, b$ : cost of abortion and birth respectively in the event of an unintended pregnancy; $a_{1}$ : heightened cost of abortion due to papal visit 
dummy variables capturing possible seasonalities. $\gamma_{p} \times t$ and $\delta_{p} \times t^{2}$, finally, represent province specific yearly linear and quadratic trends, respectively. In the most rigorous specification, we control for quarter-of-year fixed effects and province-specific quarter-of-year linear and quadratic trends.

Table 5 shows the results for the number of abortions. We observe that the estimates are stable across different specifications; reassuringly, the pre-event dummy indicators are not statistically significant at any conventional level. Focusing on our preferred specification that is also the most stringent one-column 4-we can see a

Table 5 The impact of the papal visits on abortions

\begin{tabular}{|c|c|c|c|c|}
\hline & (1) & (2) & (3) & (4) \\
\hline & \multicolumn{4}{|c|}{$\ln$ (abortions) } \\
\hline \multirow[t]{2}{*}{$\mathrm{pre}_{2}$} & -0.020 & -0.022 & -0.017 & -0.018 \\
\hline & $(0.026)$ & $(0.023)$ & $(0.026)$ & $(0.024)$ \\
\hline \multirow[t]{2}{*}{ pre $_{1}$} & 0.003 & 0.002 & -0.002 & -0.003 \\
\hline & $(0.024)$ & $(0.024)$ & $(0.025)$ & $(0.024)$ \\
\hline \multirow{2}{*}{ post $_{0}$} & -0.009 & -0.013 & -0.008 & -0.013 \\
\hline & $(0.024)$ & $(0.019)$ & $(0.024)$ & $(0.018)$ \\
\hline \multirow[t]{2}{*}{ post $_{1}$} & $-0.108^{*}$ & $-0.113^{*}$ & $-0.103^{*}$ & $-0.107^{*}$ \\
\hline & $(0.060)$ & $(0.057)$ & $(0.060)$ & $(0.057)$ \\
\hline \multirow[t]{2}{*}{ post $_{2}$} & $-0.141^{* *}$ & $-0.146^{* *}$ & $-0.138^{* *}$ & $-0.140^{* *}$ \\
\hline & $(0.066)$ & $(0.063)$ & $(0.066)$ & $(0.063)$ \\
\hline \multirow[t]{2}{*}{ post $_{3}$} & $-0.166^{* *}$ & $-0.167^{* *}$ & $-0.171^{* *}$ & $-0.174^{* * *}$ \\
\hline & $(0.065)$ & $(0.065)$ & $(0.065)$ & $(0.065)$ \\
\hline \multirow[t]{2}{*}{ post $_{4}$} & $-0.164^{* *}$ & $-0.158^{* *}$ & $-0.164^{* *}$ & $-0.159^{* *}$ \\
\hline & $(0.075)$ & $(0.076)$ & $(0.076)$ & $(0.077)$ \\
\hline \multirow[t]{2}{*}{ post $_{5}$} & -0.040 & -0.033 & -0.038 & -0.028 \\
\hline & $(0.030)$ & $(0.027)$ & $(0.030)$ & $(0.027)$ \\
\hline$N$ & 12,720 & 12,720 & 12,720 & 12,720 \\
\hline$R^{2}$ & 0.810 & 0.876 & 0.811 & 0.877 \\
\hline Province FE & Yes & Yes & Yes & Yes \\
\hline Year FE & Yes & Yes & No & No \\
\hline Calendar quarter FE & Yes & Yes & No & No \\
\hline Quarter FE & No & No & Yes & Yes \\
\hline Prov. yearly trends & No & Yes & No & No \\
\hline Prov. quarterly trends & No & No & No & Yes \\
\hline
\end{tabular}

Significance at the $10 \%$ level is represented by *, at the $5 \%$ level by ${ }^{* *}$, and at the $1 \%$ level by ***. Robust standard errors are clustered at the provincial level 
strong reduction in the number of abortions in the provinces visited by the Pope starting from the first quarter after the papal visits. The size of the effect is substantial; it varies between $-10 \%\left(\right.$ post $\left._{1}\right)$ and $-17.4 \%\left(\right.$ post $\left._{3}\right){ }^{11}$

We zoom in on the dynamics of the change in the number of abortions at the time of the papal visit by estimating a version of Eq. 1 that uses monthly counts of abortion. We include month and province fixed effects, and province-specific linear and quadratic monthly trends. For ease of exposition, we present the relevant estimates graphically for this and many of the subsequent regressions. In Fig. 5, we plot the coefficients and $95 \%$ confidence intervals for the monthly change in abortion counts starting 4 months prior to the papal visit event, and all the way up to 16 months after.

The pre-event indicators are not statistically significant at any conventional level and the size of the coefficients is close to 0 . Month 0 corresponds to the month of the visit and the coefficient is positive but small and statistically insignificant. The coefficients for months 1 and 2 are negative but also very small and statistically insignificant. The effects are much larger starting in the 3rd month and persist until the 14th month following the visit, and they are almost always statistically significant, ranging from about $-10 \%$ to almost $-20 \%$ in magnitude. ${ }^{12}$

Both the observed decrease in abortion and the timing of this effect (starts about 3 months after the visit) are consistent with the indirect effect discussed in Section 4. Unintended pregnancies start to decline about the time of the visit and this decline persists for almost 12 months. While a direct effect cannot be ruled out, the delayed decline in abortion suggests that any direct effect plays a limited role.

\subsection{Births}

We use the survey on live births carried out by the Italian National Institute of Statistics for the period 1979-2012, which collects information from the population registers of the municipalities where the birth events occurred or where the parents of the newborn normally reside, providing detailed information on the delivery of the newborn as well as socio-demographic indicators of the parents. We aggregate the number of live births at the province of birth-quarter of year level.

We estimate Eq. 1 with the log of province-level counts of live births each quarter as the dependent variable.

Table 6 displays the results. Focusing on the most rigorous specification in column 4, we fail to find evidence of any significant change in the number of births. That, in conjunction with the finding of a large decline in abortions reported in the previous section, is additional evidence that the indirect effect dominates any direct

\footnotetext{
${ }^{11}$ A possible concern is the fact that women might seek an abortion operation in a province different from the one visited by the Pope. However, this is unlikely to invalidate our results, as approximately $87 \%$ of pregnancy terminations are performed in the women's province of residence, as reported by the Minister of Health Beatrice Lorenzin during her Question Time on 19 April 2017. For the sake of completeness we have re-estimated Eq. 1 aggregating the number of abortions by the woman's province of residence. The results, available upon request, confirm the main findings presented in Table 5.

${ }^{12}$ To check how long the effect persists, we have estimated monthly specifications up to 24 months after the visit, and the estimates are close to 0 and statistically insignificant starting from the 15 th month.
} 


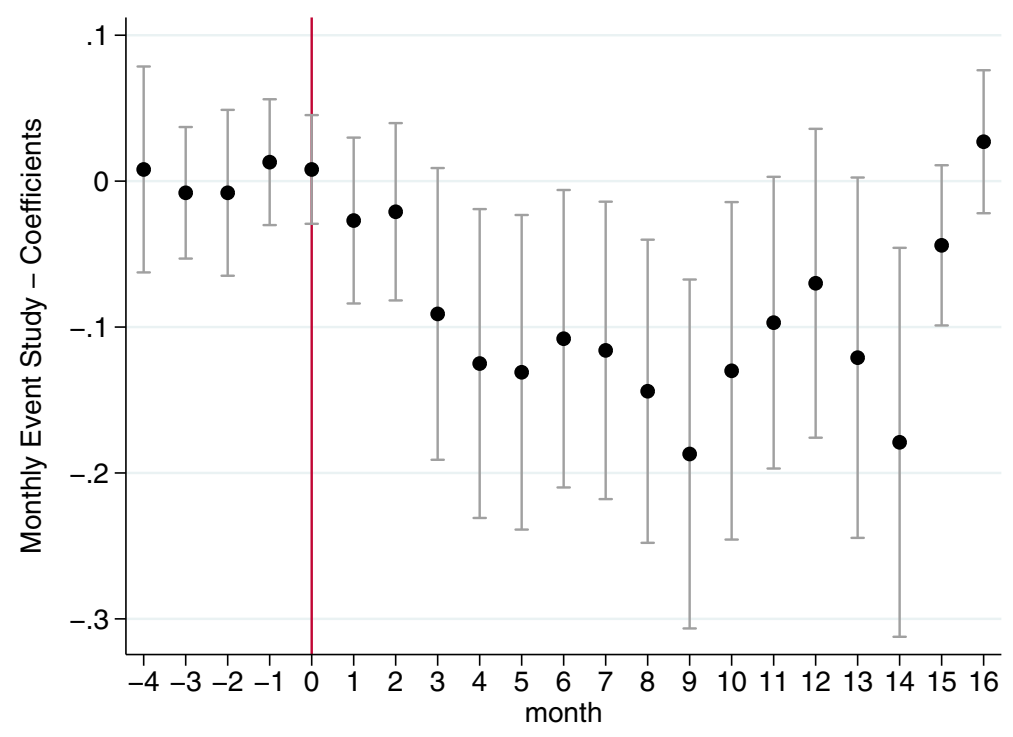

with $95 \%$ confidence interval

Fig. 5 Monthly leads and lags of impact on abortions

effect. To see this, assume that papal visits only have a direct effect of constricting abortion choices. Then, we can construct a back-of-the-envelope estimate of the ceteris paribus increase in births. In Italy during this period, on average about $20 \%$ of pregnancies were being aborted. A $15 \%$ decline in abortions implies that for every 100 pregnancies, an additional $0.15 \times 20=3$ babies would be carried to term. That in turn maps to approximately $3.7 \%$ more births. In contrast, Table 6 shows that the upper bound of the $95 \%$ confidence interval for the coefficients in the third and fourth quarter is about $1.2 \%$. In specifications using monthly counts of birth, we fail to find any significant uptick in months 8,9 or 10 following the papal visit; see Fig. 6 that shows the monthly effects on births are close to 0 and statistically insignificant.

The indirect effect predicts that the number of births will increase if there is a non-trivial fraction of type III, i.e. switchers in the population. The null finding on births suggests that among women who usually opt to abort, i.e. always-aborters and switchers, the latter make up only a small fraction (see Table 4).

\section{Mechanisms}

In this section, we provide evidence for a plausible mechanism for our findings: an increase in religiosity that persists for several months. First, we present evidence that even though the Pope resides within Italy, papal visits generate considerable excitement and media coverage in the visited areas. We also show that the impact on abortions is larger when the Pope explicitly talks about abortion during his visit, and also when he engages with the public more intensively. Next, we study how religious 
Table 6 The impact of the papal visits on births

\begin{tabular}{|c|c|c|c|c|}
\hline & (1) & (2) & (3) & (4) \\
\hline & \multicolumn{4}{|l|}{$\ln$ (births) } \\
\hline \multirow[t]{2}{*}{$\mathrm{pre}_{2}$} & 0.003 & -0.003 & 0.002 & -0.004 \\
\hline & $(0.011)$ & $(0.005)$ & $(0.011)$ & $(0.005)$ \\
\hline \multirow{2}{*}{$\mathrm{pre}_{1}$} & -0.006 & $-0.010^{*}$ & -0.007 & $-0.010^{*}$ \\
\hline & $(0.010)$ & $(0.006)$ & $(0.011)$ & $(0.006)$ \\
\hline \multirow[t]{2}{*}{ post $_{0}$} & -0.003 & $-0.010^{*}$ & 0.001 & -0.007 \\
\hline & $(0.011)$ & $(0.006)$ & $(0.011)$ & $(0.006)$ \\
\hline \multirow{2}{*}{ post $_{1}$} & 0.001 & -0.001 & 0.002 & -0.001 \\
\hline & $(0.011)$ & $(0.007)$ & $(0.011)$ & $(0.007)$ \\
\hline \multirow[t]{2}{*}{ post $_{2}$} & 0.005 & 0.002 & 0.002 & 0.000 \\
\hline & $(0.010)$ & $(0.005)$ & $(0.010)$ & $(0.005)$ \\
\hline \multirow{2}{*}{ post $_{3}$} & 0.002 & -0.001 & 0.004 & -0.000 \\
\hline & $(0.010)$ & $(0.005)$ & $(0.010)$ & $(0.005)$ \\
\hline \multirow[t]{2}{*}{ post $_{4}$} & 0.001 & -0.002 & 0.003 & 0.001 \\
\hline & $(0.010)$ & $(0.006)$ & $(0.010)$ & $(0.006)$ \\
\hline \multirow[t]{2}{*}{ post $_{5}$} & -0.008 & -0.003 & -0.007 & -0.003 \\
\hline & $(0.010)$ & $(0.006)$ & $(0.010)$ & $(0.006)$ \\
\hline$N$ & 11,896 & 11,896 & 11,896 & 11,896 \\
\hline$R^{2}$ & 0.910 & 0.979 & 0.911 & 0.979 \\
\hline Province FE & Yes & Yes & Yes & Yes \\
\hline Year FE & Yes & Yes & No & No \\
\hline Calendar quarter FE & Yes & Yes & No & No \\
\hline Quarter FE & No & No & Yes & Yes \\
\hline Prov. yearly trends & No & Yes & No & No \\
\hline Prov. quarterly trends & No & No & No & Yes \\
\hline
\end{tabular}

Significance at the $10 \%$ level is represented by *, at the $5 \%$ level by **, and at the $1 \%$ level by ${ }^{* * *}$. Robust standard errors are clustered at the provincial level

attitudes change in response to the papal visits, and document an increase in church attendance.

\subsection{Salience of papal visits}

Even though the Vatican is located within Italy, papal visits generate considerable excitement within local clergy and population, and there is intense local media coverage. We present two pieces of analyses that document the spike in media coverage of the Pope by media in the visited provinces, relative to the rest.

In the first analysis, we randomly pick four papal visits, two from the northVerona (October 2006) and Brescia (November 2009) - and two from the south of 


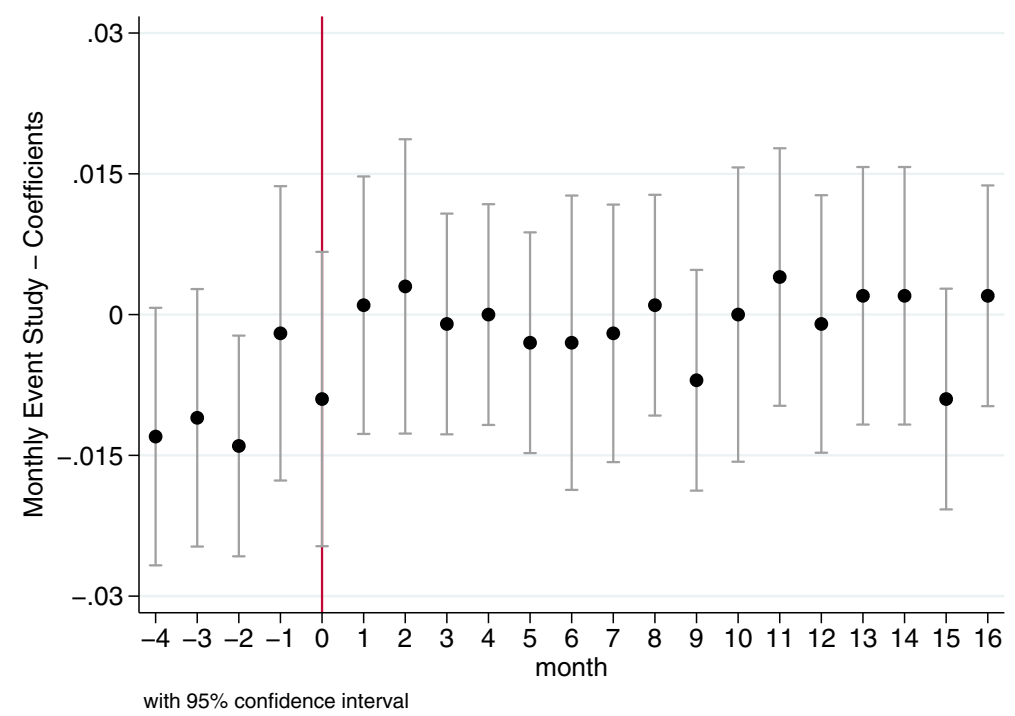

Fig. 6 Monthly leads and lags of impact on births

Italy_Bari (February 1984) and Palermo (October 2010)_and, for each of them, we count the number of articles dedicated to the Pope in (a) the local newspaper from the province visited, (b) a non-local newspaper, i.e. a local newspaper from a randomly selected province that was not visited and does not border the visited province and (c) a national newspaper, in a 7-day window enveloping the event. ${ }^{13}$

In Table 7, we show that local newspapers pay much greater attention to the visit of the Pope compared with other non-local or national newspapers. For instance, during the week of the visit to Bari in 1980, the local newspaper carried 57 articles on the Pope while the non-local and national newspapers carried only 2 each.

To give the reader a flavour of the type of coverage, Figs. 12-15 in the Online Appendix display a selection of articles extracted from the local newspapers $L a$ Gazzetta Del Mezzogiorno (Bari), L'Arena (Verona), Brescia Oggi (Brescia) and La Sicilia (Palermo).

We complement the first piece of analysis with a more systematic investigation using LexisNexis, an online media database. Ideally, we would have liked to sample news coverage from across Italy during the study period. However, LexisNexis offers access to only a few Italian newspapers, and that too for recent years. ${ }^{14}$ We select two Italian newspapers available on Lexis-Nexis since January 2009, i.e. Il Giorno

\footnotetext{
13 The local newspapers include La Gazzetta Del Mezzogiorno (Bari), L'Arena (Verona), Brescia Oggi (Brescia) and La Sicilia (Palermo). The local newspapers include Il Mattino di Napoli (Bari), Brescia Oggi (Verona), L'Arena (Brescia) and Il secolo XIX (Palermo). The national newspaper consulted for the four visit is Il Corriere della Sera.

${ }^{14}$ The reason appears to be that Italian newspapers have actively sought to monetise their news archives. Most newspapers maintain a historical archive and charge a subscription fee to read past editions; the fee depends on the number of daily issues that users wishes to access. Moreover, for the vast majority of newspapers, the archives can be accessed on the newspaper's website only.
} 
Table 7 Media coverage

\begin{tabular}{lllll}
\hline & $(1)$ & $(2)$ & $(3)$ & $(4)$ \\
\cline { 2 - 5 } & Bari & Verona & Brescia & Palermo \\
& Feb 1984 & Oct 2006 & Nov 2009 & Oct 2010 \\
\hline Local & 57 & 183 & 69 & 36 \\
Non-local & 2 & 5 & 1 & 1 \\
National & 2 & 10 & 1 & 3 \\
\hline
\end{tabular}

Each entry reports the number of newspaper articles on the Pope during the week of the visit. The local newspapers include La Gazzetta Del Mezzogiorno (Bari), L'Arena (Verona), Brescia Oggi (Brescia) and La Sicilia (Palermo). The non-local newspapers include Il Mattino di Napoli (Bari), Brescia Oggi (Verona), L'Arena (Brescia) and Il secolo XIX (Palermo). The national newspaper consulted for the four visits is $I l$ Corriere della Sera

and Il Resto del Carlino. Although these newspapers are available nationally, their readership is locally concentrated - the former in Lombardia, and the latter in EmiliaRomagna and Marche.

We construct a dataset of the monthly count of news articles on the Pope in the two newspapers for the years 2009 to 2017. There are 9 papal visits to Lombardia, Emilia-Romagna and Marche during this period. We use an event study methodology. Specifically, we estimate a negative binomial regression model with the monthly article count in a newspaper as the outcome of interest, and an event dummy that is equal to 1 if the Pope visits the region where that newspaper has wide circulation. We interact the event dummy with leads and lags so that we can trace out media response before, during and after papal visits. The regression includes fixed effects for the newspapers, month of year (e.g. Jan 2009), and newspaper-specific linear monthly trends.

Figure 7 shows the estimated change in local newspaper coverage in the months surrounding a visit. There is no detectable difference in local vs. non-local newspapers coverage in the 2 months prior to the visit. Coverage spikes during the month of the visit; the local newspaper carries on average 24 more articles on the Pope. The effect is quite large, as this represents the $72 \%$ of the average number of articles on the Pope. The increase in local coverage remains statistically significant until the 2 nd month after the visit before dropping back to normal.

To sum up, there appears to be a clear pattern of intensified coverage of the Pope in the local newspapers during papal visits. ${ }^{15}$

\subsection{Content of papal speeches}

The content of papal speeches is typically in line with mainstream Catholic doctrine and, as a consequence, the speeches do not provide any new information to Catholics.

\footnotetext{
${ }^{15}$ Unfortunately, we do not have information on TV and radio coverage of such events; nonetheless, it is reasonable to expect local broadcasters to devote more time to the visit of the Pope.
} 


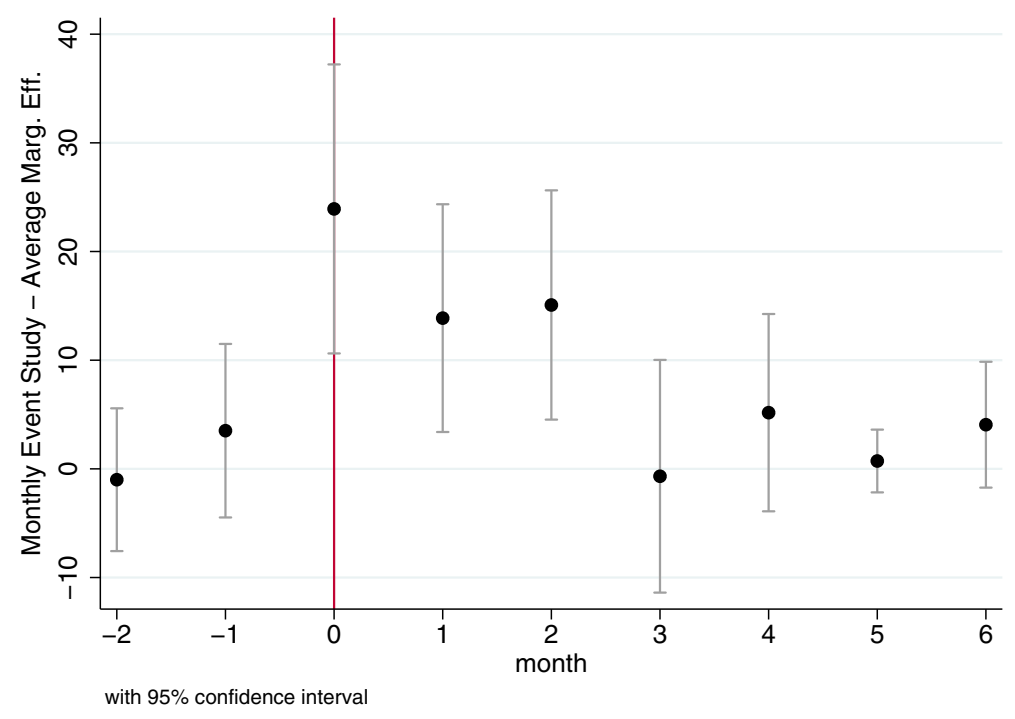

Fig. 7 Monthly leads and lags of impact on media coverage

Nonetheless, as remarked by Bassi and Rasul (2017), non-informative dimensions of communication can influence belief formation through salience, attention and framing.

Using the information made available by the Vatican papal archives, we study how frequently the Pope talks about abortion. In about $25.4 \%$ of the visits, the Pope talks about abortion explicitly or implicitly by using expressions such as "sanctity of human life since its conception" or "protection of human life in the womb". We also count the mention of other plausibly relevant keywords: "family", "sex" or "contraception" and "chastity". The Pope refers to family in approximately the $95.4 \%$ of his visits, confirming the centrality of the family unit according to the Catholic doctrine. The frequency is considerably lower for the other words: "sex" or "contraception" $(8.1 \%)$, and "chastity" (13.3\%).

We then investigate whether the impact is larger for visits during which the Pope talks about abortion. Table 8 shows that the estimated decline in abortions is more than twice as large for such visits.

Another dimension of the papal visit that might matter is the intensity of his engagement with the public. The Pope typically makes several public speeches during a visit; the median number of speeches is 5. We re-estimate Eq. 1, separately for visits during which the Pope made less than or more than 5 speeches. The results presented in the Appendix A-Table 13 show that the decline in abortions is larger following papal visits with more speeches. ${ }^{16}$

\footnotetext{
${ }^{16} \mathrm{We}$ thank an anonymous referee for suggesting the analyses of the content and frequency of papal speeches.
} 
Table 8 The impact of the papal visits on abortions when the pope mentions abortion

\begin{tabular}{|c|c|c|}
\hline & (1) & (2) \\
\hline & Abortion not mentioned & Abortion mentionec \\
\hline \multirow[t]{2}{*}{$\mathrm{pre}_{2}$} & -0.035 & 0.033 \\
\hline & $(0.028)$ & $(0.062)$ \\
\hline \multirow[t]{2}{*}{$\mathrm{pre}_{1}$} & 0.002 & -0.010 \\
\hline & $(0.029)$ & $(0.055)$ \\
\hline \multirow[t]{2}{*}{ post $_{0}$} & -0.010 & -0.006 \\
\hline & $(0.021)$ & $(0.054)$ \\
\hline \multirow[t]{2}{*}{ post $_{1}$} & -0.094 & -0.129 \\
\hline & $(0.067)$ & $(0.132)$ \\
\hline \multirow[t]{2}{*}{ post $_{2}$} & -0.081 & $-0.283^{*}$ \\
\hline & $(0.066)$ & $(0.164)$ \\
\hline \multirow[t]{2}{*}{ post $_{3}$} & $-0.130^{*}$ & $-0.277^{*}$ \\
\hline & $(0.071)$ & $(0.157)$ \\
\hline \multirow[t]{2}{*}{ post $_{4}$} & -0.133 & -0.215 \\
\hline & $(0.092)$ & $(0.154)$ \\
\hline \multirow[t]{2}{*}{ post $_{5}$} & 0.010 & -0.118 \\
\hline & $(0.022)$ & $(0.093)$ \\
\hline$N$ & 12,720 & 12,720 \\
\hline$R^{2}$ & 0.876 & 0.877 \\
\hline No. of visits & 129 & 44 \\
\hline Province FE & Yes & Yes \\
\hline Quarter FE & Yes & Yes \\
\hline Prov. quarterly trends & Yes & Yes \\
\hline
\end{tabular}

Significance at the $10 \%$ level is represented by ${ }^{*}$, at the $5 \%$ level by ${ }^{* *}$, and at the $1 \%$ level by ${ }^{* * *}$. Robust standard errors are clustered at the provincial level

\subsection{Impact on religiosity}

We have argued that papal visits heighten the stigma attached to abortions. We now present evidence that papal visits have an impact on religiosity, using the repeated cross-section annual survey Aspects of daily life made publicly available by the Italian National Institute of Statistics. The survey interviews every year a sample of 20,000 Italian households (roughly corresponding to 50,000 individuals) on key aspects of daily life and behaviour. The sampling strategy follows a two-stage stratification aimed at constructing a sample representative at the national, macro-area (North-West, North-East, Centre, South and Isles) and regional level.

From 1993 to 2003, the data were collected during the month of November, while starting from 2005, it was run in February. The survey did not take place in 2004. The survey explores multiple facets of daily life such as respondents' religious, political 
and social participation, allowing us to conduct the analysis at the regional level, corresponding to NUTS-2 regions according to the European Union classification. In total, there are 20 regions with each region made up of multiple provinces. ${ }^{17,18}$

We focus our analysis on women and exploit the section on religious participation, where individuals are asked to report the frequency of church attendance, and generate a binary indicator taking the value 1 if the respondent reports going to church at least once a week and 0 otherwise. ${ }^{19}$

We estimate the following linear probability specification:

$$
Y_{i, r, y}=\beta_{1} \text { Pope }_{r, y}^{0-3}+\beta_{2} \text { Pope }_{r, y}^{4-16}+\delta X_{i, r, y}+\gamma_{r} \times t+\iota_{r} \times t^{2}+\theta_{r}+\theta_{y}+u_{i, r, y}
$$

where $Y_{i, r, y}$ is an indicator for weekly church attendance for respondent $i$ in region $r$ in year $y ; X_{i, r, y}$ includes individual-level observable characteristics such as age, education, gender, unemployment status and marital status; $\gamma_{r} \times t$ and $\iota_{r} \times t^{2}$ are regional yearly trends, $\theta_{r}$ and $\theta_{y}$ are region and year fixed effects. The variables Pope $\mathrm{e}_{r, y}^{0-3}$ and $\mathrm{Pope}_{r, y}^{4-16}$ are event dummies. The former, $\mathrm{Pope}_{r, y}^{0-3}$, takes the value 1 if the respondent was surveyed within 3 months of a papal visit to the respondent's region. The latter, Pope ${ }_{r, y}^{4-16}$, takes the value 1 if the papal visit took place 4 to 16 months prior to the date of survey. Thus, $\beta_{1}$ and $\beta_{2}$ aim to capture the short-run and the more long-run effects of the papal visit on church attendance.

We estimate Eq. 2 for the full sample and, separately, for women and men. Table 9 displays the results. Women show a significant increase in the frequency of church attendance following a papal visit. However, this increase does not appear to persist beyond 3 months after the papal visit. On the contrary, no effect is detected for men. ${ }^{20}$

The findings on increased church attendance are consistent with the findings on reduced abortions, and support heightened religiosity as a potential mechanism. However, the drop in abortions persists for up to 14 months after a papal visit but we do not see a corresponding persistence in the increase in religiosity. We are unable to offer a fully satisfactory explanation for the duration of the behavioural change driving the fall in abortions. We do note though that there is considerable measurement error in estimating Eq. 2 since the event dummies are constructed at the regional level, and regions are amalgamations of several provinces. We would expect the coefficients to be biased towards 0. Additionally, there is evidence that the effects of participating in major religious events can be salient for several months; Clingingsmith et al. (2009) find significant effects on religious practices and social attitudes of Muslim pilgrims, 5 to 8 months after participating in the Hajj pilgrimage to Mecca.

\footnotetext{
${ }^{17}$ The regions exert legislative power on matters not expressly reserved to state law. Regions are made of several provinces, with the only exception of Aosta Valley, where the provincial functions are fulfilled by the regional government.

${ }^{18}$ The survey Aspects of daily life incorporates two regions, Piedmont and Aosta Valley, in a unique administrative body.

${ }^{19}$ The precise question asked is, "How often do you go to the Church or other place of worship?" The respondent can pick from two options: (1) at least once a week, or (2) less than once a week.

${ }^{20}$ In the Appendix A-Table 14, we test whether the differential effect for married and unmarried is statistically significant. We do so by re-estimating Eq. 2 while pooling the two groups and interacting the event dummies with a dummy for marital status. We cannot reject the null of no difference in effects for married and unmarried.
} 
Table 9 The impact of the papal visits on religiosity

\begin{tabular}{llll}
\hline & $(1)$ & $(2)$ & $(3)$ \\
\cline { 2 - 3 } & Total sample & Women & Men \\
\hline Panel A: All & & & \\
Pope Event $^{0-3}$ & 0.004 & $0.011^{* *}$ & -0.004 \\
& $(0.004)$ & $(0.005)$ & $(0.004)$ \\
Pope Event ${ }^{4-16}$ & -0.002 & -0.001 & -0.003 \\
Mean Dep. Var. & $(0.003)$ & $(0.003)$ & $(0.003)$ \\
$N$ & 0.333 & 0.418 & 0.243 \\
$R^{2}$ & 828,900 & 426,164 & 402,736 \\
Controls & 0.090 & 0.075 & 0.044 \\
Region FE & Yes & Yes & Yes \\
Year FE & Yes & Yes & Yes \\
Regional yearly trends & Yes & Yes & Yes \\
\hline
\end{tabular}

Significance at the $10 \%$ level is represented by $*$, at the $5 \%$ level by $* *$, and at the $1 \%$ level by $* * *$. Results of OLS regressions of a dummy for weekly church attendance on indicators for papal visits 0-3 and 4-16 months before the survey response on church attendance. Individual weights provided by ISTAT were applied. Controls include age, marital status, gender (column 1), education level and unemployment status. Robust standard errors are clustered at the region-year level

\section{Discussion}

To recap, we find a large and statistically significant decrease in abortions, ranging from -10 to $-20 \%$, that commences about 3 months after the papal visit and persists until the 14th month. We do not find any subsequent uptick in live births. The findings taken together suggest a strong indirect effect—papal visits induce a reduction in unintended pregnancies that starts around the time of the visits and persists for almost 1 year. In contrast, any direct effects of restriction in demand and/or supply of abortion appear to play limited role.

We have been agnostic whether the decrease in unintended pregnancies is being driven by increased abstinence or increased usage of contraceptives; we have bundled both behaviours as contraception. Despite extensive search, we were unable to locate extant Italian household survey data that would allow us to measure how papal visits affect the frequency of sexual intercourse or usage of contraceptives. But even if surveys were available, one would have to be careful in interpreting behavioural changes that would be the net effects of an increased desire for intended pregnancy among some women and also an increased aversion to unintended pregnancy among other women. ${ }^{21}$

\footnotetext{
${ }^{21}$ If the survey gathered information on desired fertility in the short or long run, one could in principle condition on that, and test whether post-visit there is a fall in unintended pregnancies among women who report not wanting another child.
} 
In discussing the indirect effect, two other features of Church doctrine are relevant. First, the Church regards sexual intercourse as a sin if conducted outside sacramental marriage, or, even within wedlock, if deprived of its procreative function. Therefore, during and after papal visits, women might practise more abstinence unless they are planning on getting pregnant. Note that this is separate type of stigma that would independently drive down unintended pregnancies. Second, the Church explicitly discourages contraceptive usage because it breaks the connection between sex and reproduction within marriage and encourages recreational sex out of wedlock. ${ }^{22}$ For women seeking to minimise the risk of an unintended pregnancy, this poses a dilemma. One way out is to more abstinence. But some may opt for more usage of contraceptives as the "lesser of two evils". Therefore, a mix of both behavioursmore abstinence and more contraceptive usage - may be driving the reduction in unintended pregnancies.

Thus far, we have assumed that all women have the chance to modify their behaviour in response to papal visits. But there is also a group of women who would have gotten pregnant before the papal visit became salient, and detected the (unintentional) pregnancy shortly before or after the visit. Faced with an increased cost of abortion, some women who would have chosen to abort might opt not to do so. We would then expect to see a contemporaneous drop in abortion, albeit smaller than the subsequent decline, and a spike in births 9 months later. But we find no such effects. It appears that, if already pregnant, papal visits do not change women's abortion decisions. In other words, even the heightened cost of abortion is less than the cost of an unwanted birth. Looking back at the model in Section 4 (and Table 4), we can infer that among women who choose to abort, most are type II (always-aborters) and only a few are type III (switchers). Earlier, we had drawn the same inference from the lack of increase in births reported in Section 5.2. It is worth noting that the proportion of switchers is endogenous to the change in the cost of abortion; the greater the increase, the higher that proportion. The fact that switchers form only a small proportion suggests that the heightened stigma of abortion from papal visits is not sufficiently large to induce women to switch away from abortions, conditional on being pregnant.

Could our findings be driven by under-reporting? ${ }^{23}$ Stigma could drive women to switch to "back-street" abortion providers to keep the procedure secret. We cannot rule out under-reporting as a factor but it is unlikely to be the main explanation for our findings. With under-reporting, one would expect to see a drop in abortions contemporaneous with the papal visit.

How do our findings compare to those reported in the recent paper by Bassi and Rasul (2017) on the effect of the papal visit to Brazil in 1991? Their methodology is different from ours. For identification, they exploit the fortuitous timing of the 1991 DHS survey in Brazil which was fielded in the weeks before, during and after the

\footnotetext{
${ }^{22}$ In the Encyclical Letter Humanae Vitae, Paul VI (n.d.) in reference to contraceptives states that "human beings - and especially the young, who are so exposed to temptation - need incentives to keep the moral law, and it is an evil thing to make it easy for them to break that law".

${ }^{23}$ The share of illegal abortions in Italy is non-trivial although it has fallen over time. According to Grandolfo et al. (2009), illegal abortions in 1983 accounted for about $30 \%$ of total voluntary pregnancy terminations. The figures released by the Ministry of Health (2017) confirm a decrease in the share of illegal abortions, estimated to be under $14 \%$ in 2012.
} 
papal visit. They study how short-run beliefs and long-run behaviour of individuals respond to the papal persuasion. They report a substantial increase in the frequency of sexual intercourse, and a large reduction in the use of contraceptives among women interviewed post-visit. The net effect is a $26 \%$ increase in the frequency of unprotected sex that drives a positive fertility response with a spike in births 9 months post-visit. In contrast, in the Italian setting, we find no net effect on births. One plausible explanation for the difference is that a papal visit to Brazil is a much bigger event because it is so rare. This could have much larger effects on the perceived costs of abortion as well as on fertility preferences of Brazilian women.

As already noted, abortion ratios are highest among teenagers (see Table 2). We test how teen abortions respond to papal visits. The findings are reported in the Appendix A-Table 15. The effect on abortions is smaller for teenagers; there is a statistically significant decline of about $10 \%$ in the third quarter following the visit but no significant declines in other periods. We also test for the impact separately by age group, education level and marital status. The results are summarised in Appendix A, Figs. 9, 10 and 11. In general, the effects appear similar across groups except for a few differences. The decline appears to be larger for married women than for unmarried ones, and to a lesser degree, for less educated women versus higher educated ones. The finding of smaller effects for unmarried women is not surprising given what we find for teens, who likely make up a big part of the unmarried group. However, when we use pooled regressions to explicitly test whether the difference between married versus unmarried is statistically significant, we cannot reject the null of similar sized effects. The same is true for the difference by education level.

\subsection{Is there a pattern to papal visits?}

We ask whether papal visits are planned in response to underlying trends in abortions or religiosity. The concern is that if the Pope is more likely to visit provinces that are exhibiting a trend of relatively increasing religiosity (and concurrently a decreasing relative abortion rate), our estimate of the impact is not 'causal' but merely reflects this underlying trend.

First, we note that our identification strategy relies on the precise timing of the event, and in the preferred specifications, we control for province-specific quadratic time trends. Reassuringly, we find no discernible effect in the quarters (or months) preceding the event. Hence, we would argue that our estimates can be credibly inferred as causal.

Nevertheless, the time and place of a papal visit are unlikely to be random. ${ }^{24}$ The decision made by the Pope to visit a place could be driven by specific factors, e.g.

\footnotetext{
${ }^{24}$ In fact, most papal visits are planned well in advance. See for example the article by the Archdiocese of Baltimore (n.d.) at the following link: https://www.archbalt.org/planning-papal-trips-takes-diplomacycollaboration-fine-tuning/.
} 
Table 10 Factors influencing the papal visits

(1)

(2)

(3)

$\operatorname{Pr}($ Pope Event=1)

\begin{tabular}{ll}
\hline$\Delta_{1}$ Abortions $_{p, y-1}$ & -0.002 \\
& $(0.003)$
\end{tabular}

$\% \Delta_{2}$ Abortions $_{p, y-1}$ 0.007

(0.006)

$\% \Delta_{5}$ Abortions $_{p, y-1}$

N

3146

3037

2823

$R^{2}$

0.147

0.178

0.183

$\% \Delta_{1}$ Births $_{p, y-1}$

0.058

(0.069)

$\% \Delta_{2}$ Births $_{p, y-1}$

$\% \Delta_{5}$ Births $_{p, y-1}$

0.016

$\mathrm{N}$

2,969

2,859

2,850

$R^{2}$

0.140

0.157

0.161

$\% \Delta_{1}$ Religiosity $_{r, y-1}$

$-0.259$

(0.222)

$\% \Delta_{2}$ Religiosity $_{r, y-1}$

$\% \Delta_{5}$ Religiosity $_{r, y-1}$

$N$

$R^{2}$

Province or region FE

Yes

Yes

Yes

\section{Year FE}

Yes

Yes

Yes

Prov. or region yearly trends

Yes

Yes

Prov. or region visited before

Yes

Yes

Yes

Significance at the $10 \%$ level is represented by $*$, at the $5 \%$ level by $* *$ and at the $1 \%$ level by $* * *$. Results of OLS regressions of a dummy for papal visits to a province (region) in a given year on preceding trends in abortions (panel A), births (panel B) and religiosity (panel C). Controls include a dummy $=1$ if the province (region) was visited in the 1,2 or 5 years preceding the visit, province (region) and year fixed effects and provincial (regional) yearly trends. Robust standard errors are clustered at the provincial (regional) level 
Table 11 The impact of the papal visits on abortions (years 1997 and 1998 excluded)

\begin{tabular}{|c|c|c|c|c|}
\hline & (1) & (2) & (3) & (4) \\
\hline & \multicolumn{4}{|c|}{$\ln ($ abortions $)$} \\
\hline \multirow[t]{2}{*}{ pre $_{2}$} & -0.016 & -0.021 & -0.013 & -0.016 \\
\hline & $(0.026)$ & $(0.023)$ & $(0.027)$ & $(0.024)$ \\
\hline \multirow[t]{2}{*}{ pre $_{1}$} & 0.005 & 0.000 & 0.001 & -0.004 \\
\hline & $(0.025)$ & $(0.024)$ & $(0.025)$ & $(0.024)$ \\
\hline \multirow[t]{2}{*}{ post $_{0}$} & -0.007 & -0.015 & -0.006 & -0.014 \\
\hline & $(0.025)$ & $(0.020)$ & $(0.025)$ & $(0.019)$ \\
\hline \multirow[t]{2}{*}{ post $_{1}$} & $-0.110^{*}$ & $-0.119^{* *}$ & $-0.105^{*}$ & $-0.113^{*}$ \\
\hline & $(0.061)$ & $(0.059)$ & $(0.062)$ & $(0.059)$ \\
\hline \multirow[t]{2}{*}{ post $_{2}$} & $-0.139^{* *}$ & $-0.147^{* *}$ & $-0.135^{* *}$ & $-0.142^{* *}$ \\
\hline & $(0.067)$ & $(0.064)$ & $(0.067)$ & $(0.064)$ \\
\hline \multirow[t]{2}{*}{ post $_{3}$} & $-0.163^{* *}$ & $-0.167^{* *}$ & $-0.168^{* *}$ & $-0.173^{* * *}$ \\
\hline & $(0.066)$ & $(0.066)$ & $(0.066)$ & $(0.066)$ \\
\hline \multirow[t]{2}{*}{ post $_{4}$} & $-0.163^{* *}$ & $-0.160^{* *}$ & $-0.164^{* *}$ & $-0.162^{* *}$ \\
\hline & $(0.076)$ & $(0.077)$ & $(0.077)$ & $(0.078)$ \\
\hline \multirow[t]{2}{*}{ post $_{5}$} & -0.036 & -0.030 & -0.034 & -0.026 \\
\hline & $(0.030)$ & $(0.027)$ & $(0.030)$ & $(0.027)$ \\
\hline$N$ & 11,896 & 11,896 & 11,896 & 11,896 \\
\hline$R^{2}$ & 0.805 & 0.873 & 0.805 & 0.873 \\
\hline Province FE & Yes & Yes & Yes & Yes \\
\hline Year FE & Yes & Yes & No & No \\
\hline Calendar quarter FE & Yes & Yes & No & No \\
\hline Quarter FE & No & No & Yes & Yes \\
\hline Prov. yearly trends & No & Yes & No & No \\
\hline Prov. quarterly trends & No & No & No & Yes \\
\hline
\end{tabular}

Significance at the $10 \%$ level is represented by *, at the $5 \%$ level by ** and at the $1 \%$ level by ***. Robust standard errors are clustered at the provincial level

motivated by the desire to reverse a general decline in religiosity among the local population that leads to an increasing abortion rate. If so, a papal visit may coincide with other (unobserved) ongoing activities by the Church in that province and during that time that could be driving our results.

We test whether the Pope is more likely to visit a province or region that exhibits an increase in the number of abortions or a decrease in the number of births or in the level of religiosity in the 1,2 or 5 years preceding the papal event, using the following specification:

$$
\operatorname{Pr}(\text { Pope Event } \text { E }, y=1)=\alpha+\beta \% \Delta_{i} Z_{p, y-1}+\gamma_{p} \times t+\delta_{p} \times t^{2}+\theta_{p}+\theta_{a}+u_{p, y}
$$




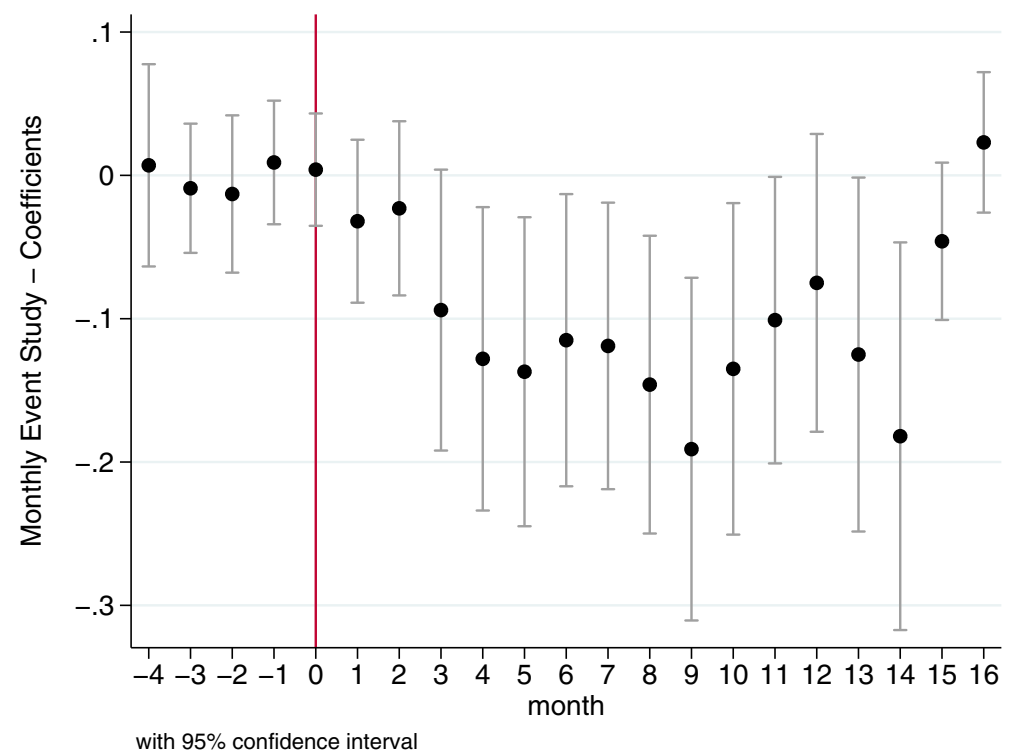

Fig. 8 Monthly leads and lags of impact on abortions (provinces never visited excluded)

where Pope Event ${ }_{p, y}$ is a binary indicator taking the value 1 if province $p$ was visited by the Pope in year $y ; \% \Delta_{i} Z_{p, y-1}$ represents the percentage change in the number of abortions, births or in the average religiosity indicator, as defined in Section 6.3 , over the 1,2 or 5 years preceding the visit of the Pope in province $p$, $\gamma_{p} \times t$ and $\delta_{p} \times t^{2}$ are provincial yearly trends; $\theta_{p}$ and $\theta_{y}$ are province and year fixed effects. ${ }^{25}$

Table 10 displays the results from estimating Eq. 3. Starting from panel A, the papal visits do not respond to any pre-trend in the number of abortions registered in the 1, 2 or 5 years preceding the visit to a specific province. We repeat the same exercise to test whether the papal visits are influenced by changes in births (panel B) or religiosity (panel C). Also, in these cases, no statistically significant effect is detected. Overall, the results bolster confidence that our main findings are causal effects of papal visits and not merely picking up underlying trends in local religiosity and Church activities.

\subsection{Additional tests}

As a first test, we re-estimate Eq. 1 for abortions excluding the years 1997-1998. We do so because the analysis of live births does not include those years (see Section 3,

\footnotetext{
25 The analysis on religiosity is conducted at the regional level, as explained in Section 6.3.
} 
Table 12 The impact of the papal visits on abortions by gestational age

\begin{tabular}{lll}
\hline & $(1)$ & $(2)$ \\
\cline { 2 - 3 } & $\leq 90$ days & $>90$ days \\
\hline pre $_{2}$ & -0.016 & 0.037 \\
& $(0.024)$ & $(0.046)$ \\
pre $_{1}$ & -0.002 & -0.015 \\
& $(0.023)$ & $(0.067)$ \\
post $_{0}$ & -0.010 & -0.039 \\
& $(0.018)$ & $(0.056)$ \\
post $_{1}$ & $-0.107^{*}$ & -0.030 \\
& $(0.057)$ & $(0.042)$ \\
post $_{2}$ & $-0.139^{* *}$ & -0.015 \\
& $(0.064)$ & $(0.048)$ \\
post $_{3}$ & $-0.174^{* * *}$ & -0.026 \\
& $(0.066)$ & $(0.047)$ \\
post $_{4}$ & $-0.159^{* *}$ & -0.016 \\
post $_{5}$ & $(0.077)$ & $(0.046)$ \\
& -0.029 & 0.012 \\
$N$ & $(0.028)$ & $(0.050)$ \\
$R^{2}$ & 12,720 & 12,720 \\
Province FE $_{\text {Quarter FE }}$ & 0.875 & 0.734 \\
Prov. quarterly trends & Yes & Yes \\
\hline & Yes & Yes \\
\hline
\end{tabular}

Significance at the $10 \%$ level is represented by ${ }^{*}$, at the $5 \%$ level by ${ }^{* *}$ and at the $1 \%$ level by ${ }^{* * *}$. Robust standard errors are clustered at the provincial level

p. 11). As shown in Table 11, the results for abortion remain essentially unchanged (compare with Table 5). Second, we re-estimate Eq. 1 for monthly abortion counts excluding provinces that were never visited by the Pope. Again, as shown in Fig. 8, we get similar results to those displayed in Fig. 5 .

Finally, we would not expect abortions induced for medical reasons to be substantially affected by papal visits. The data does not explicitly identify such abortions. However, legally, any abortions after the foetus is 3 months old can only be 
performed on medical grounds. We know the age of the foetus at the time of abortion. In Table 12. we show the impact on abortions for foetus aged less than 3 months (largely voluntary) and those aged more than 3 months (medically necessary). The latter serves as a placebo test-there is no impact on such abortions.

\section{Conclusions}

We find that papal visits to Italian provinces cause a 10 to $20 \%$ decline in the number of abortions, starting in the 3rd month after the visit and persisting until around the 14th month after. We argue that the decline in abortions is being primarily driven by a reduction in unintended pregnancies. We offer two main pieces of evidence for this explanation. First, the timing of the effect-the drop in abortions is not contemporaneous with papal visits. Instead, abortions start decreasing about 3 months after the visit which would approximately coincide with the timing of abortions for unintended pregnancies that occur during the papal visit. Second, ceteris paribus, given the abortion rate in Italy, the large fall in abortions would translate into a measurable increase in the number of live births. But we fail to find any discernible increase in live births 9 months after the visit. Taken together, the timing of the effect and the lack of an increase in births point towards a decline in unintended pregnancies as the most plausible explanation.

The Church has consistently maintained a strong stance against abortion. This is well known and a papal visit does not provide new information on the stigma attached to abortion. But the visit can make this stigma salient and thereby increase the perceived cost of abortion. We furnish a number of pieces of supporting evidence. First, papal visits generate intense local media coverage. Second, the measured impact on abortions is larger when the Pope mentions abortion, and also when he more actively engages with the public, as proxied by the number of public speeches during a visit. Third, the visits lead to heightened religiosity, as proxied by weekly church attendance.

We document that papal visits have large effects that persist for several months. Our preferred explanation points to major behavioural changes among women (and couples in general) lasting for almost a year. Our findings contribute to the growing literature that demonstrates the powerful role that religion continues to play in people's lives.

Acknowledgements We are grateful to Andy McKay, David de Meza, Hector Gutierrez Rufrancos, Imran Rasul, Matthew Embrey, Pawel Dziewulski, Paola Manzini and Stefano DellaVigna for helpful comments along with participants at the 2018 Royal Economic Society meeting and the economics departmental seminar at the University of Sussex. We also sincerely thank Maria Santorsa, Roberto Ielpo and all the staff at Laboratorio Adele of the Italian National Institute of Statistics (ISTAT) for their assistance in facilitating access to the datasets used in this work. Data processing and economic analysis have been carried out at the regional data centre of Laboratorio Adele in Basilicata, in obedience with applicable confidentiality rules. ISTAT does not bear any responsibility for the views expressed here. 


\section{Compliance with ethical standards}

Conflict of interest The author declare that they have no conflict of interest.

Open Access This article is licensed under a Creative Commons Attribution 4.0 International License, which permits use, sharing, adaptation, distribution and reproduction in any medium or format, as long as you give appropriate credit to the original author(s) and the source, provide a link to the Creative Commons licence, and indicate if changes were made. The images or other third party material in this article are included in the article's Creative Commons licence, unless indicated otherwise in a credit line to the material. If material is not included in the article's Creative Commons licence and your intended use is not permitted by statutory regulation or exceeds the permitted use, you will need to obtain permission directly from the copyright holder. To view a copy of this licence, visit http://creativecommons.org/licenses/by/4.0/.

\section{Appendix A}

Table 13 The impact of the papal visits on abortions by number of speeches

\begin{tabular}{|c|c|c|}
\hline & (1) & (2) \\
\hline & Speeches $<5$ & Speeches $\geq 5$ \\
\hline \multirow[t]{2}{*}{$\mathrm{pre}_{2}$} & -0.033 & 0.004 \\
\hline & $(0.034)$ & $(0.038)$ \\
\hline \multirow[t]{2}{*}{ pre $_{1}$} & -0.023 & 0.029 \\
\hline & $(0.037)$ & $(0.024)$ \\
\hline \multirow[t]{2}{*}{ post $_{0}$} & -0.026 & 0.011 \\
\hline & $(0.029)$ & $(0.024)$ \\
\hline \multirow[t]{2}{*}{ post $_{1}$} & -0.084 & -0.126 \\
\hline & $(0.062)$ & $(0.117)$ \\
\hline \multirow[t]{2}{*}{ post $_{2}$} & -0.047 & $-0.253^{*}$ \\
\hline & $(0.061)$ & $(0.130)$ \\
\hline \multirow[t]{2}{*}{ post $_{3}$} & -0.105 & $-0.251^{* *}$ \\
\hline & $(0.065)$ & $(0.124)$ \\
\hline \multirow[t]{2}{*}{ post $_{4}$} & -0.063 & $-0.268^{*}$ \\
\hline & $(0.064)$ & $(0.147)$ \\
\hline \multirow[t]{2}{*}{ post $_{5}$} & -0.002 & -0.051 \\
\hline & $(0.031)$ & $(0.049)$ \\
\hline$N$ & 12,720 & 12,720 \\
\hline$R^{2}$ & 0.876 & 0.877 \\
\hline Province FE & Yes & Yes \\
\hline Quarter FE & Yes & Yes \\
\hline Prov. quarterly trends & Yes & Yes \\
\hline
\end{tabular}

Significance at the $10 \%$ level is represented by ${ }^{*}$, at the $5 \%$ level by ${ }^{* *}$ and at the $1 \%$ level by ${ }^{* * *}$. Robust standard errors are clustered at the provincial level 
Table 14 The impact of the papal visits on religiosity (differential effect by marital status)

\begin{tabular}{|c|c|c|c|}
\hline & \multirow{2}{*}{$\frac{(1)}{\text { Total sample }}$} & \multirow{2}{*}{$\frac{(2)}{\text { Women }}$} & \multirow{2}{*}{$\frac{(3)}{\text { Men }}$} \\
\hline & & & \\
\hline \multirow[t]{2}{*}{ Pope Event ${ }^{0-3} \times$ Married } & -0.013 & -0.023 & 0.001 \\
\hline & $(0.021)$ & $(0.023)$ & $(0.016)$ \\
\hline \multirow[t]{2}{*}{ Pope Event ${ }^{4-16} \times$ Married } & 0.004 & 0.003 & 0.006 \\
\hline & $(0.008)$ & $(0.008)$ & $(0.007)$ \\
\hline$N$ & 828,900 & 426,164 & 402,736 \\
\hline$R^{2}$ & 0.090 & 0.075 & 0.044 \\
\hline Controls & Yes & Yes & Yes \\
\hline Region FE & Yes & Yes & Yes \\
\hline Year FE & Yes & Yes & Yes \\
\hline Regional Yearly Trends & Yes & Yes & Yes \\
\hline
\end{tabular}

Significance at the $10 \%$ level is represented by $*$, at the $5 \%$ level by $* *$ and at the $1 \%$ level by $* * *$. Results of OLS regressions of a dummy for weekly church attendance on indicators for papal visits 0-3 and 4-16 months before the survey response on church attendance, interacted with the marital status of the respondent (the unmarried are the excluded category). Individual weights provided by ISTAT were applied. Controls include age, gender (column 1), education level and unemployment status. Robust standard errors are clustered at the region-year level 
Table 15 The impact of the papal visits on abortions for teenage women

\begin{tabular}{|c|c|c|c|c|}
\hline & (1) & (2) & (3) & (4) \\
\hline & \multicolumn{4}{|c|}{$\ln$ (abortions) } \\
\hline \multirow[t]{2}{*}{ pre $_{2}$} & 0.017 & -0.011 & 0.014 & -0.013 \\
\hline & $(0.032)$ & $(0.026)$ & $(0.033)$ & $(0.028)$ \\
\hline \multirow[t]{2}{*}{ pre $_{1}$} & 0.014 & -0.012 & 0.021 & -0.006 \\
\hline & $(0.034)$ & $(0.033)$ & $(0.036)$ & $(0.035)$ \\
\hline \multirow[t]{2}{*}{ post $_{0}$} & 0.006 & -0.020 & 0.011 & -0.015 \\
\hline & $(0.034)$ & $(0.032)$ & $(0.035)$ & $(0.032)$ \\
\hline \multirow[t]{2}{*}{ post $_{1}$} & -0.019 & -0.051 & -0.017 & -0.046 \\
\hline & $(0.039)$ & $(0.034)$ & $(0.037)$ & $(0.032)$ \\
\hline \multirow[t]{2}{*}{ post $_{2}$} & 0.006 & -0.024 & 0.006 & -0.023 \\
\hline & $(0.040)$ & $(0.034)$ & $(0.040)$ & $(0.035)$ \\
\hline \multirow[t]{2}{*}{ post $_{3}$} & $-0.080^{* *}$ & $-0.104^{* * *}$ & $-0.079^{* *}$ & $-0.105^{* * *}$ \\
\hline & $(0.037)$ & $(0.037)$ & $(0.037)$ & $(0.036)$ \\
\hline \multirow[t]{2}{*}{ post $_{4}$} & -0.029 & -0.044 & -0.024 & -0.040 \\
\hline & $(0.049)$ & $(0.047)$ & $(0.048)$ & $(0.046)$ \\
\hline \multirow[t]{2}{*}{ post $_{5}$} & 0.004 & -0.016 & 0.008 & -0.007 \\
\hline & $(0.037)$ & $(0.031)$ & $(0.037)$ & $(0.031)$ \\
\hline$N$ & 12,720 & 12,720 & 12,720 & 12,720 \\
\hline$R^{2}$ & 0.782 & 0.855 & 0.788 & 0.861 \\
\hline Province FE & Yes & Yes & Yes & Yes \\
\hline Year FE & Yes & Yes & No & No \\
\hline Calendar Quarter FE & Yes & Yes & No & No \\
\hline Quarter FE & No & No & Yes & Yes \\
\hline Prov. yearly trends & No & Yes & No & No \\
\hline Prov. quarterly trends & No & No & No & Yes \\
\hline
\end{tabular}

Significance at the $10 \%$ level is represented by $*$, at the $5 \%$ level by $* *$ and at the $1 \%$ level by $* * *$. Robust standard errors are clustered at the provincial level 


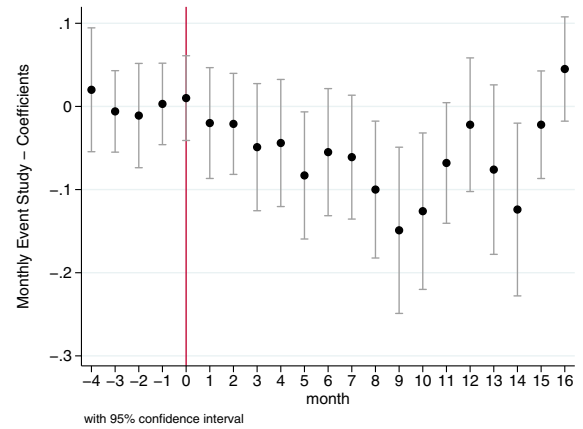

(a) Age $\leq 24$

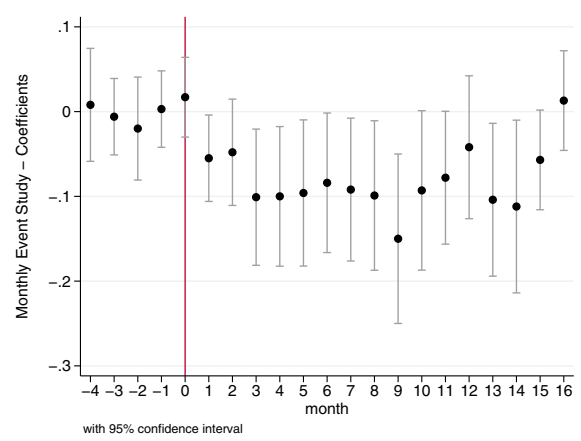

(c) Age $\geq 35$

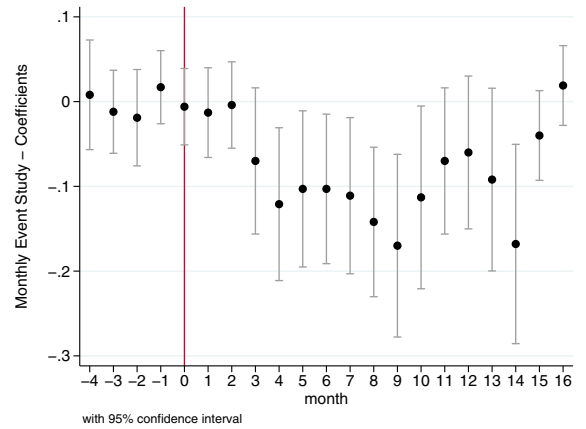

(b) $25 \leq$ Age $\leq 34$

Fig. 9 Monthly leads and lags of impact on abortions by age category

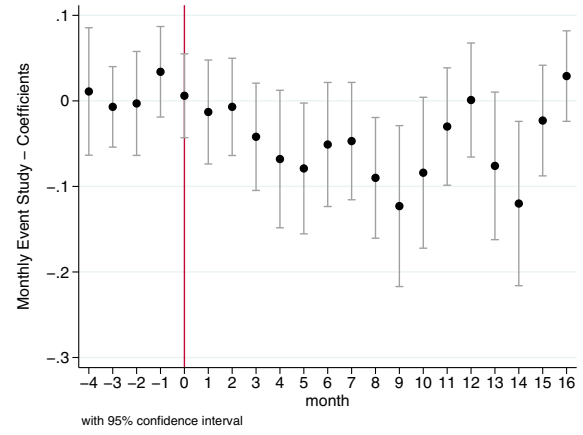

(a) Unmarried

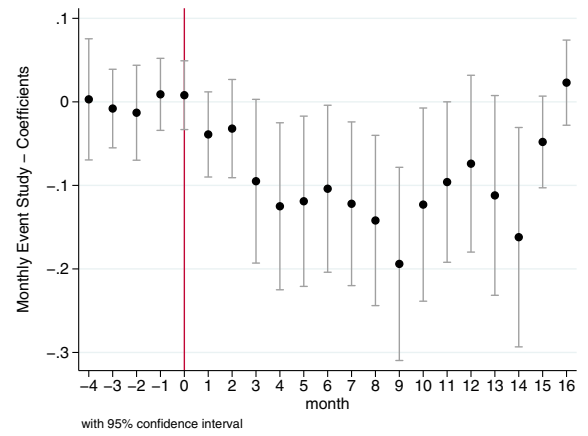

(b) Married

Fig. 10 Monthly leads and lags of impact on abortions by marital status 


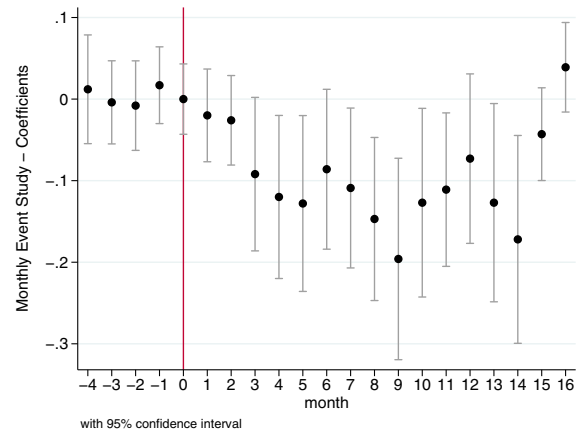

(a) Low Education

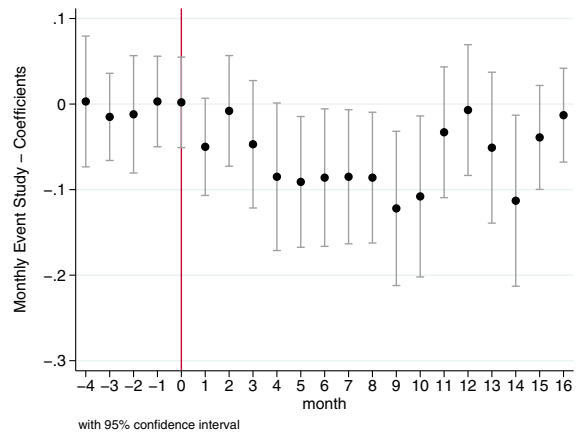

(b) High Education

Fig. 11 Monthly leads and lags of impact on abortions by educational status 


\section{Appendix B}

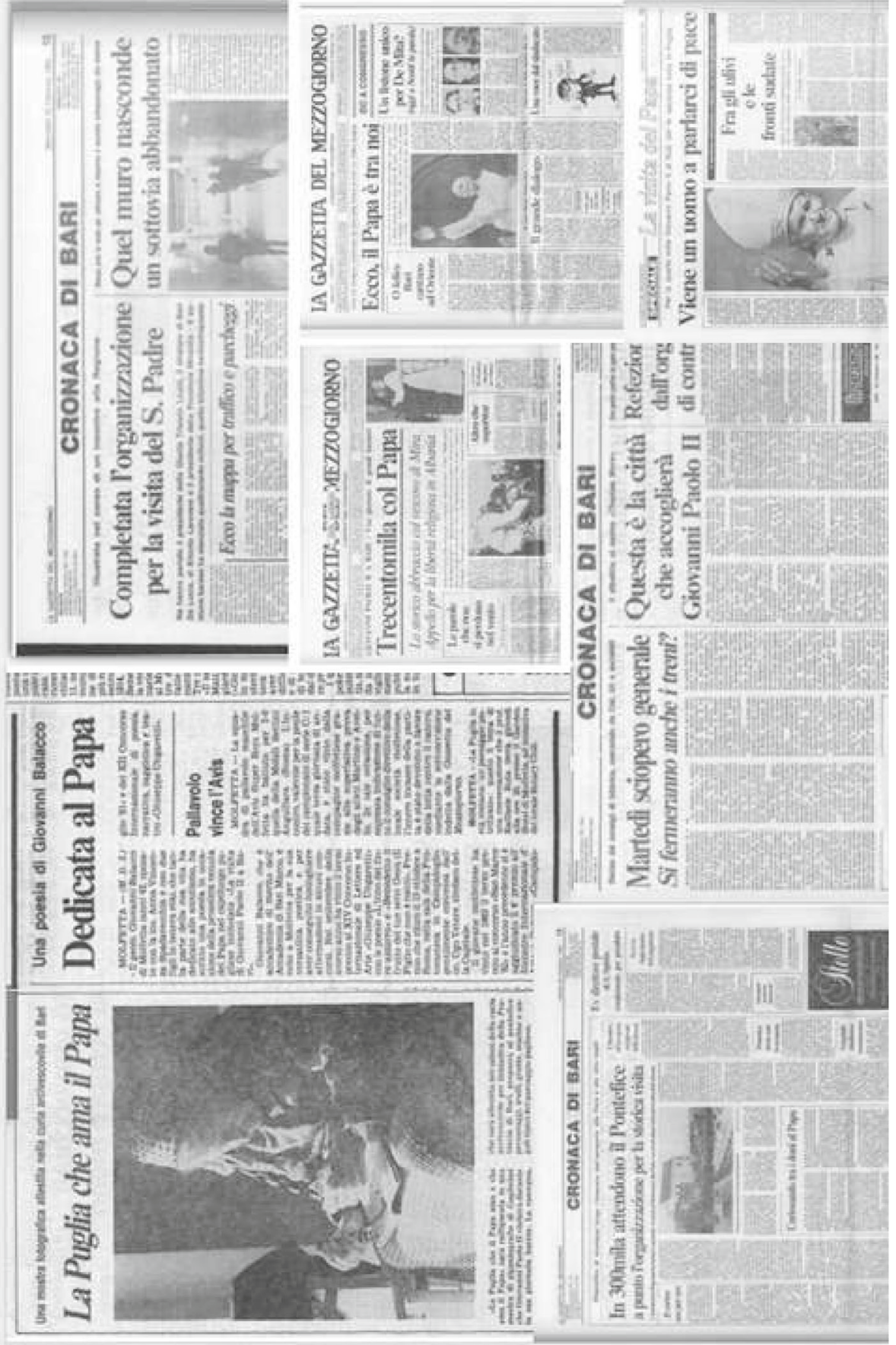

Fig. 12 Papal Visits to Bari (February 1984) 

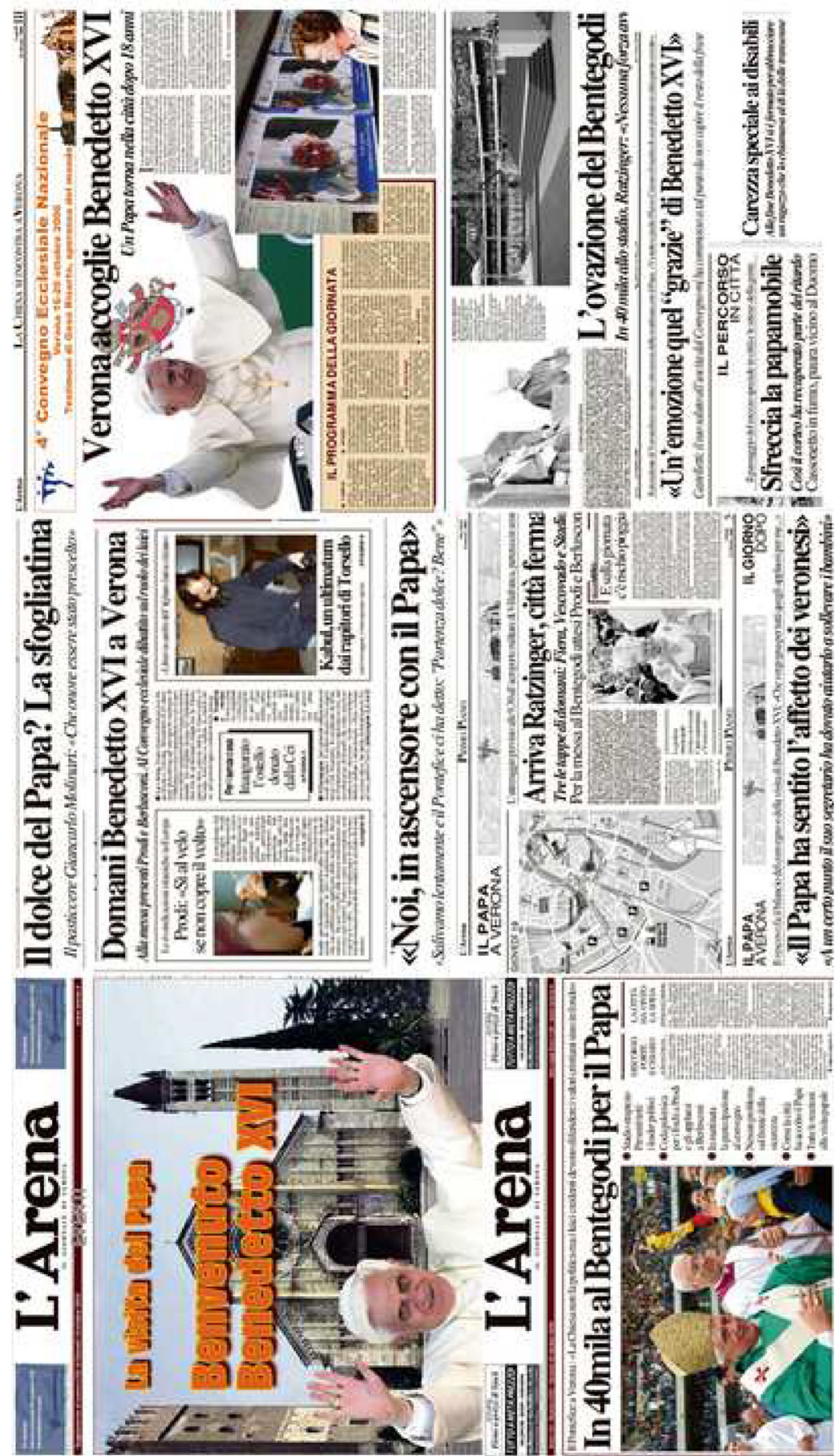

Fig. 13 Papal Visits to Verona (October 2006) 

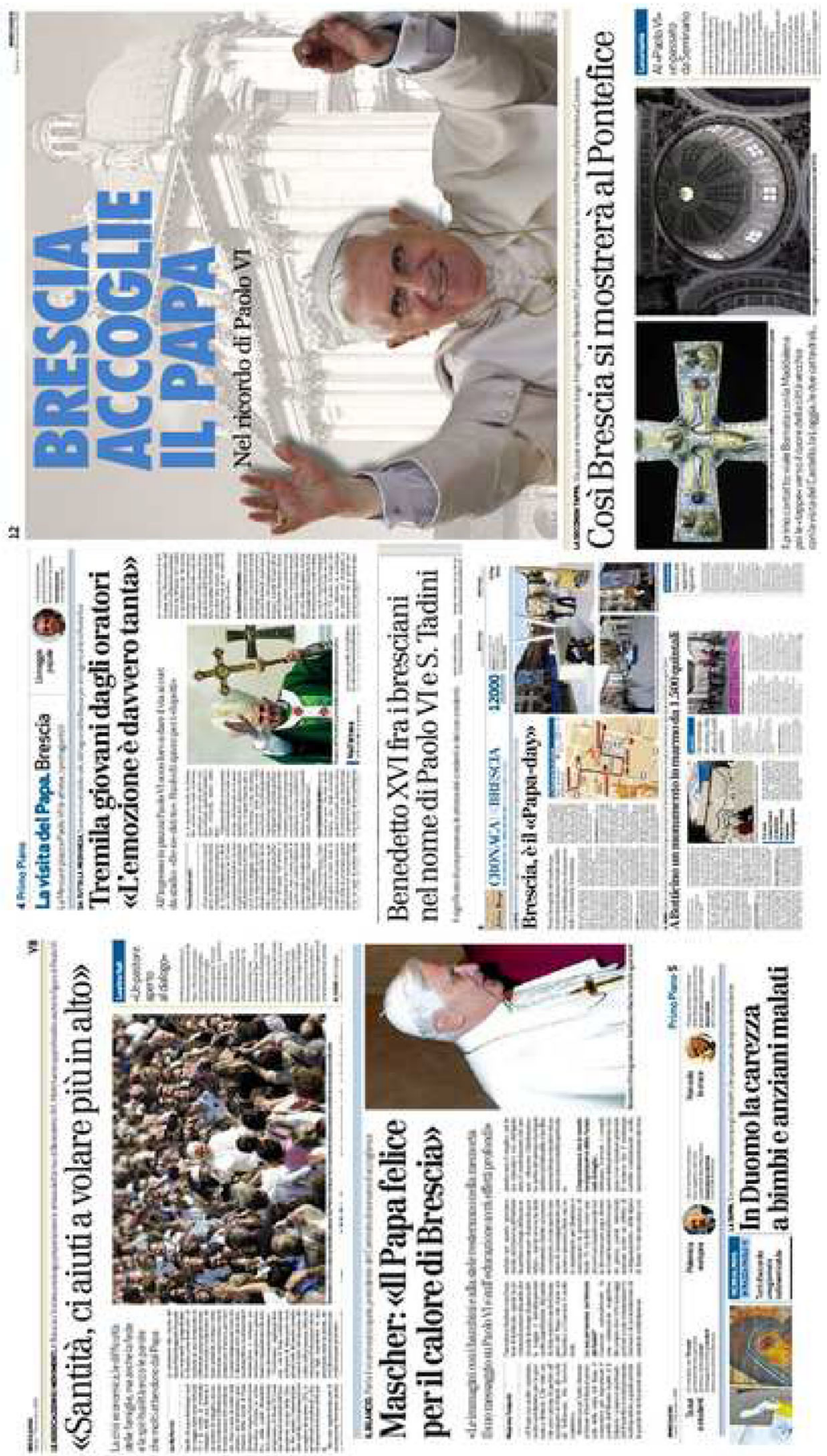

Fig. 14 Papal Visits to Brescia (November 2009) 

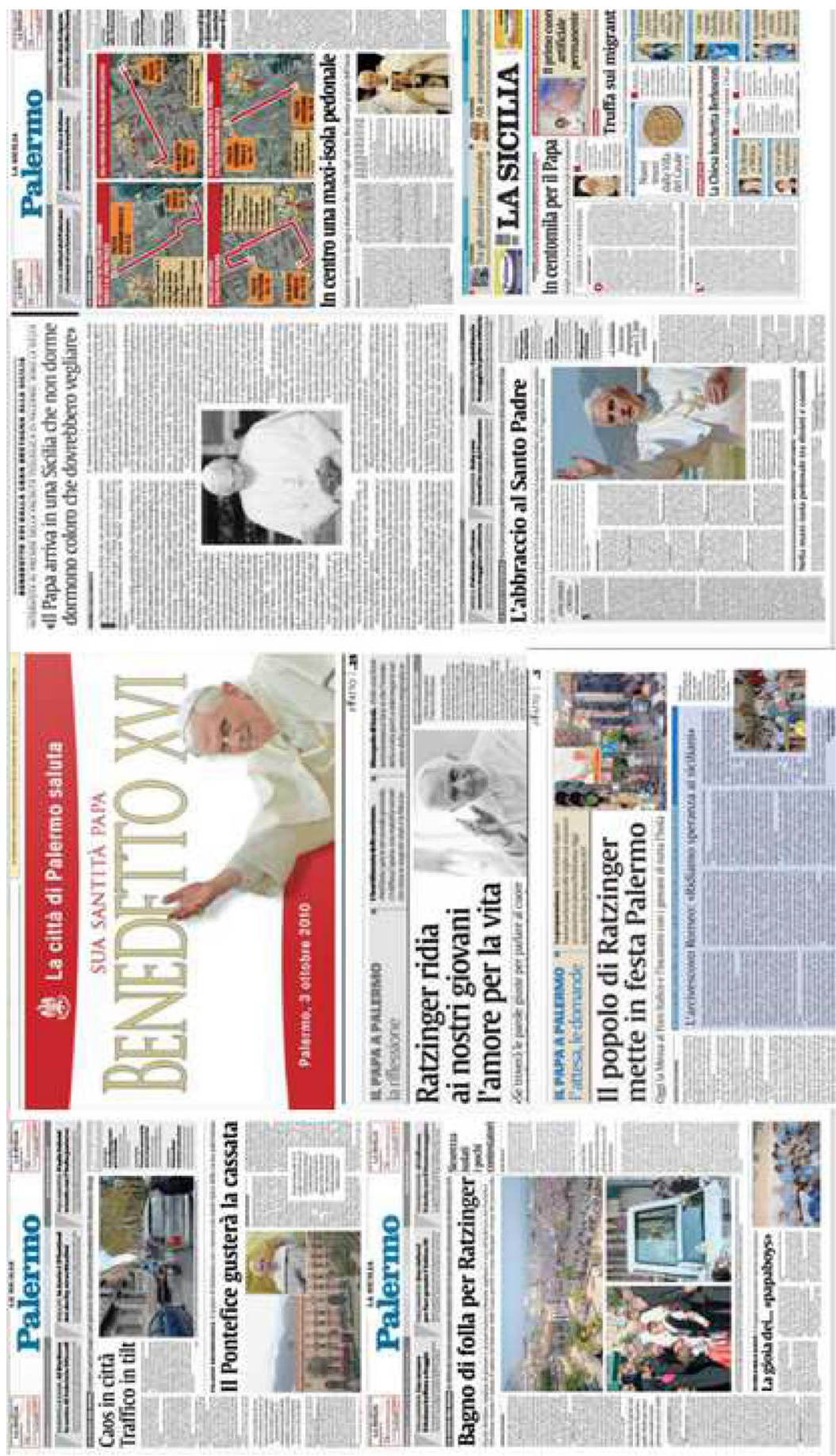

Fig. 15 Papal Visits to Palermo (October 2010) 
Open Access This article is distributed under the terms of the Creative Commons Attribution 4.0 International License (http://creativecommons.org/licenses/by/4.0/), which permits unrestricted use, distribution, and reproduction in any medium, provided you give appropriate credit to the original author(s) and the source, provide a link to the Creative Commons license, and indicate if changes were made.

\section{References}

Abramowitz J (2018) Planning parenthood: the affordable care act young adult provision and pathways to fertility. J Population Econ 31(4):1097-1123. https://doi.org/10.1007/s00148-017-0676-6

Almond D, Mazumder B (2011) Health capital and the prenatal environment: the effect of ramadan observance during pregnancy. American Econ J Appl Econ 3(4):56-85. https://doi.org/10.1257/app.3. 4.56

Archdiocese of Baltimore (n.d.) Planning papal trips takes diplomacy, collaboration, fine-tuning. Available at: https://www.archbalt.org/planning-papal-trips-takes-diplomacy-collaboration-fine-tuning/

Bassi V, Rasul I (2017) Persuasion: a case study of papal influences on fertility-related beliefs and behavior. American Econ J Appl Econ 9(4):250-302. http://www.aeaweb.org/articles?id=10.1257/ app. 20150540

Beaman L, Chattopadhyay R, Duflo E, Pande R, Topalova P (2009) Powerful women: does exposure reduce bias? Quarterly J Econ 124(4):1497-1540. https://doi.org/10.1162/qjec.2009.124.4.1497

Beaman L, Duflo E, Pande R, Topalova P (2012) Female leadership raises aspirations and educational attainment for girls: a policy experiment in India. Science 335(6068):582-586. http://science. sciencemag.org/content/335/6068/582

Becker GS (1991) A treatise on the family. Harvard University Press. https://books.google.co.uk/books? id=NLB1Ty75DOIC

Benjamin DJ, Choi JJ, Fisher G (2016) Religious identity and economic behavior. Rev Econ Stat 98(4):617-637. https://doi.org/10.1162/REST_a_00586

Bertrand M, Schoar A (2003) Managing with style: the effect of managers on firm policies. Quarterly J Econ 118(4):1169-1208. https://doi.org/10.1162/003355303322552775

Blank RM, George CC, London RA (1996) State abortion rates the impact of policies, providers, politics, demographics, and economic environment. J Health Econ 15(5):513-553. http://www.sciencedirect. com/science/article/pii/S0167629696004948

Catechism of the Catholic Church (n.d.) Life In Christ. Available at: http://www.vatican.va/archive/ccc css/archive/catechism/p3s2c2a6.htm

Clingingsmith D, Khwaja AI, Kremer M (2009) Estimating the impact of the Hajj: religion and tolerance in Islam's global gathering. Quarterly J Econ 124(3):1133-1170. https://doi.org/10.1162/qjec.2009. 124.3.1133

Coleman PK, Coyle CT, Shuping M, Rue VM (2009) Induced abortion and anxiety, mood, and substance abuse disorders: Isolating the effects of abortion in the national comorbidity survey. J Psychiatric Res 43(8):770-776

Danesi G (n.d.) Giovanni Paolo II il Papa Globetrotter. Available at: http://www.ilgazzettinodelviaggiatore. it/magazine/editoriale/220-giovanni-paolo-ii-il-papa-globetrotter.html

DellaVigna S (2010) The Obama effect on economic outcome: evidence from event studies., unpublished Manuscript. Available at: https://eml.berkeley.edu/sdellavi/wp/obama10-07-08.pdf

Eurispes (2016) Rapporto Italia 2016. La sindrome del Palio. Available at: https://eurispes.eu/content/ rapporto-italia-2016-la-sindrome-del-palio

Finer LB, Henshaw SK (2006) Disparities in rates of unintended pregnancy in the United States, 1994 and 2001. Perspectives on Sexual and Reproductive Health 38(2):90-96. https://doi.org/10.1363/ 3809006

Grandolfo M, Spinelli A, Pediconi M, Timperi F, Andreozzi S, Bucciarelli M (2009) Il sistema di sorveglianza epidemiologica dell'interruzione volontaria di gravidanza. 22(5):3-7. Available at: http://www. epicentro.iss.it/temi/materno/pdf/Ivg_Iss.pdf

Grossman D, White K, Hopkins K, Potter J (2017) Change in distance to nearest facility and abortion in Texas, 2012 to 2014. JAMA 317 (4), 437-439. https://doi.org/10.1001/jama.2016.17026 
Iannaccone LR (1998) Introduction to the economics of religion. J Econ Lit 36(3):1465-1495. http://www. jstor.org/stable/2564806

Iyer S (2016) The new economics of religion. J Econ Lit 54(2):395-441. http://www.aeaweb.org/articles? id $=10.1257 /$ jel.54.2.395

John Paul II (1981) Familiaris Consortio. Available at: http://w2.vatican.va/content/john-paul-ii/en/apost_ exhortations/documents/hf_jp-ii_exh_19811122_familiaris-consortio.html

Jones BF, Olken BA (2005) Do leaders matter? National leadership and growth since world war II. Quarterly J Econ 120(3):835-864. https://doi.org/10.1093/qje/120.3.835

Joyce T (2011) The supply-side economics of abortion. New England J Med 365(16):1466-1469. https://doi.org/10.1056/NEJMp1109889

Joyce T, Kaestner R (1996) State reproductive policies and adolescent pregnancy resolution: the case of parental involvement laws. J Health Econ 15(5):579-607. http://www.sciencedirect.com/science/ article/pii/S0167629696004961

Levine PB (2003) Parental involvement laws and fertility behavior. J Health Econ 22(5):861-878. http:// www.sciencedirect.com/science/article/pii/S0167629603000638

Levine PB (2004) Sex and consequences: abortion, public policy, and the economics of fertility. Princeton University Press, Princeton

Levine PB, Trainor AB, Zimmerman DJ (1996) The effect of Medicaid abortion funding restrictions on abortions, pregnancies and births. J Health Econ 15(5):555-578. http://www.sciencedirect.com/ science/article/pii/S016762969600495X

Lindo JM, Myers C, Schlosser A, Cunningham S (2017) How far is too far? New evidence on abortion clinic closures, access, and abortions. Working Paper 23366, National Bureau of Economic Research. http://www.nber.org/papers/w23366

Majid MF (2015) The persistent effects of in utero nutrition shocks over the life cycle: evidence from ramadan fasting. J Development Econ 117:48-57. http://www.sciencedirect.com/science/article/pii/ S030438781500067X

McCleary RM, Barro RJ (2006) Religion and economy. J Econ Perspectives 20(2):49-72. http://www. aeaweb.org/articles?id=10.1257/jep.20.2.49

Ministry of Health (2017) Available at: http://www.salute.gov.it/imgs/C_17_pubblicazioni_2686_allegato. pdf

Norris A, Bessett D, Steinberg JR, Kavanaugh ML, De Zordo S, Becker D (2011) Abortion stigma: a reconceptualization of constituents, causes, and consequences. Women's Health Issues 21(3):S49-S54

Oosterbeek H, van der Klaauw B (2013) Ramadan, fasting and educational outcomes. Econ Education Rev 34:219-226. http://www.sciencedirect.com/science/article/pii/S0272775712001501

Paul VI (n.d.) Humanae Vitae. Available at: http://w2.vatican.va/content/paul-vi/en/encyclicals/ documents/hf_p-vi_enc_25071968_humanae-vitae.html

Ratzinger J (1987) Available at: http://www.vatican.va/roman_curia/congregations/cfaith/documents/rc_ con_cfaith_doc_19870222_respect-for-human-life_en.html

Rosenzweig MR, Schultz TP (1983) Consumer demand and household production: the relationship between fertility and child mortality. American Econ Rev 73(2):38-42. http://www.jstor.org/stable/ 1816811

Schünmann C, Glasier A (2006) Measuring pregnancy intention and its relationship with contraceptive use among women undergoing therapeutic abortion. Contraception 73(5):520-524. http://www. sciencedirect.com/science/article/pii/S0010782406000047

Sedgh G, Bearak J, Singh S, Bankole A, Popinchalk A, Ganatra B, Rossier C, Gerdts C, Tunçalp Ö, Johnson BR Jr, Johnston HB, Alkema L (2016) Abortion incidence between 1990 and 2014: global, regional, and subregional levels and trends. The Lancet 388(10041):258-267. http://dx.doi.org/10. 1016/S0140-6736(16)30380-4

Singh S, Sedgh G, Hussain R (2010) Unintended pregnancy: worldwide levels, trends, and outcomes. Studies in Family Planning 41(4):241-250. https://doi.org/10.1111/j.1728-4465.2010.00250.x

Stroebel J, van Benthem A (2012) The power of the church - the role of roman catholic teaching in the transmission of HIV, unpublished Manuscript. https://doi.org/10.2139/ssrn.2018071

Topkis DM (1978) Minimizing a submodular function on a lattice. Operations Research 26(2):305-321. https://doi.org/10.1287/opre.26.2.305

Vezzoni C, Biolcati-Rinaldi F (2015) Church attendance and religious change in Italy, 1968-2010: a multilevel analysis of pooled datasets. Journal for the Scientific Study of Religion 54(1):100-118. https://doi.org/10.1111/jssr.12173 
Wertman DA (1982) The Catholic Church and Italian politics: the impact of secularisation. West European Politics 5(2):87-107. https://doi.org/10.1080/01402388208424359

Publisher's note Springer Nature remains neutral with regard to jurisdictional claims in published maps and institutional affiliations. 